\title{
7 Differentialdiagnose
}

\subsection{Frühkindlicher Autismus Kanner und andere Autismusformen, tiefgreifende Entwicklungsstörungen (PDD)}

\section{Historisches}

In Kapitel 1 wurde bereits darauf hingewiesen, dass vor allem im angloamerikanischen Schrifttum in der DSM-II-Ära unter dem Begriff „childhood schizophrenia“ ein sehr breites Spektrum psychotiformer Entwicklungsstörungen des Kindesalters subsumiert wurden. Es handelte sich dabei um ein ganzes Syndrom-Cluster, welches sich im Wesentlichen auf Störungen der sprachlichen, motorischen und kognitiven Entwicklung bezog sowie auf phänomenologische Auffälligkeiten wie sprachliche und motorische Stereotypien und Manierismen, bizarre Körperhaltungen, Gangauffälligkeiten (z.B. Zehengang), Wedeln mit Händen und Armen, Ritualbildungen, Echolalie, Phonographismus, Mutismus, Kontaktstörungen (Autismus oder symbiotische Beziehungsmuster), affektive Teilnahmslosigkeit, unmotivierte Wutausbrüche oder Lachanfälle.

Kolvin (1971) und Werry (1979) haben dann aber die kindliche Schizophrenie eindeutig von Entwicklungsstörungen wie dem frühkindlichen Autismus (Kanner) und sog. pervasiven Entwicklungsstörungen (PDD) unterschieden, was auch Grundlage der DSM-IIIKlassifikation wurde. Dadurch ist es in dieser Frage zu einer Annäherung an die klassische deutsche bzw. zentraleuropäische Kinderpsychiatrie gekommen, und die Diagnose einer kindlichen Schizophrenie orientierte sich an der entsprechenden klassischen Psychopathologie des Erwachsenenalters. Im Übrigen hat L. Kanner (1943) das von ihm erstmalig beschriebene und nach ihm benannte Krankheitsbild des frühkindlichen Autismus nie in einen Zusammenhang mit der kindlichen Schizophrenie gebracht, wie dies spätere Autoren wie z.B. L. Bender (1947) oder R. Lempp (1973) getan haben. 


\subsubsection{Frühkindlicher Autismus Kanner}

Der frühkindliche Autismus Kanner wird heute zu den sog. tiefgreifenden Entwicklungsstörungen (ICD-10:F84) bzw. Pervasive Development Disorders (PDD) - DSM-IV: 299 gerechnet. Dazu gehören die in Tabelle 11 aufgelisteten Entwicklungsstörungen des Kindesalters.

\section{Tab. 11 Tiefgreifende Entwicklungsstörungen des Kindesalters nach Bölte u. Poustka (mit freundlicher Genehmigung von Springer Science+Business Media: Petermann F, Niebamk K, Scheithauer H (Hrsg.) Entwicklungswissenschaft, Tiefgreifende Entwicklungsstörungen, 2004, Bölte S und Poustka F)}

\begin{tabular}{ll} 
ICD-10 & DSM-IV \\
frühkindlicher Autismus (F84.0) & Autistische Störung (299.00) \\
\hline Asperger-Syndrom (F84.5) & Asperger-Störung (299.80) \\
\hline atypischer Autismus (F84.1) & $\begin{array}{l}\text { NNB* Tiefgreifende Entwicklungsstörung (NNB-TE; } \\
\text { 299.80) }\end{array}$ \\
\hline Rett-Syndrom (F84.2) & Rett-Störung (299.80) \\
\hline $\begin{array}{l}\text { andere desintegrative Störungen des Kindesalters } \\
\text { (F84.3) }\end{array}$ & Desintegrative Störung im Kindesalter (299.10) \\
\hline $\begin{array}{l}\text { überaktive Störung mit Intelligenzminderung und } \\
\text { Bewegungstereotypien (F84.4) }\end{array}$ & Keine Entsprechung im DSM-IV \\
\hline $\begin{array}{l}\text { sonstige tiefgreifende Entwicklungsstörungen (F84.8) } \\
\text { nicht näher bezeichnete tiefgreifende Entwicklungs- } \\
\text { störung (F84.9) }\end{array}$ & NNB-TE \\
\hline $\begin{array}{l}\text { *NNB = nicht näher bezeichnete Störung; Restkategorie, die diagnostiziert wird, wenn z.B. das Symptombild nicht } \\
\text { vollständig erfüllt wird, das Symptombild als solches nicht in den Störungskategorien vollständig abgebildet ist, } \\
\text { aber ein klinisch bedeutsames Leiden vorliegt }\end{array}$ \\
\hline
\end{tabular}

Die Hauptsymptome des frühkindlichen Autismus sind:

1. Beziehungsstörungen mit Unfähigkeit der normalen Kontaktaufnahme mit der personalen und dinglichen Umwelt, wobei sich häufig bis zur Faszination gesteigerte selektionierte Spezialinteressen an bestimmten bevorzugten Gegenständen (besonderes Spielzeug, Türgriff, Stofflappen, Schnur u.ä.) herausbilden können.

2. Tendenz zur Bewahrung der Gleichheit der Umwelt und der Situation, in der sich das Kind befindet, oft verbunden mit zwanghaften Ritualisierungen von Verhaltensweisen, Veränderungsangst.

3. Sprachstörungen: Echolalie, Phonographismus, Wortverstümmelungen oder -neubildungen, Agrammatismen, pronominale Umkehr, Störungen in der Erfassung von Lauten und im Verständnis von Sprache; nur etwa zwei Drittel der autistischen Kinder sind fähig zum Spracherwerb.

4. Intelligenzstörung als Folge der affektiven Blockade des beziehungsgestörten Kindes und/oder einer kognitiven Dysfunktion mit oder ohne Vorliegen einer manifesten Zerebralschädigung. Man unterscheidet in Abhängigkeit von der intellektuellen Entwicklung einen „high functioning Autismus“ ohne wesentliche Intelligenzminderung oder mit Lernbehinderung (IQ>70) von einem „low functioning Autismus" (IQ < 70). Bei etwa 3\% liegt die Intelligenz im Normbereich, bei etwa $17 \%$ im Grenzbereich, etwa $20 \%$ sind lernbehindert (IQ $<85)$ und etwa 60\% weisen eine geistige Behinderung auf (IQ $<70)$. 
7.1 Frühkindlicher Autismus Kanner und andere Autismusformen, tiefgreifende Entwicklungsstörungen (PDD)

5. Abnorme Reaktionen auf sensorische Reize mit Neigung zu Kinästhesien, Perzeptionsstörungen. Typisch sind sensorische Selbststimulationen z.B. in Form von kräftigem Bohren mit dem Finger in die Augen, um Photome zu erzeugen, oder stereotypes u.U. stundenlanges Wedeln mit gespreizten Fingern vor den Augen.

6. Motorische Auffälligkeiten mit Manierismen, geschraubt-eckig-steifen Bewegungen, Stereotypien, Grimassieren. Extremer Zehenspitzengang oder stundenlanger Kopfstand (u.U. > 12 Stunden!). Die Kinder haben eine ausgeprägte Neigung zu Selbstverletzungen (Beißen, Schlagen mit dem Kopf gegen Wand oder Fußboden, Boxhiebe gegen das Gesicht).

Die Symptomatik zeigt sich für gewöhnlich von der Geburt an oder in der frühen Säuglingszeit, fast stets jedoch vor dem 2./3. Lebensjahr. Die Prognose ist ungünstig, sie ist abhängig von der Intelligenz- und Sprachentwicklung sowie vom Vorliegen und vom Ausmaß hirnorganischer Schädigungen.

Die wesentlichen Unterscheidungsmerkmale gegenüber einer frühkindlichen Schizophrenie sind folgende Gegebenheiten:

- Erkrankungsbeginn

- Knabenwendigkeit

- familiäre Belastung

- sehr seltener Übergang in eine schizophrene Psychose

Eine kindliche Schizophrenie kann vor dem 6./7. Lebensjahr nicht mit hinreichender Sicherheit diagnostiziert werden bzw. ist in dieser Altersstufe extrem selten! Bei strenger Diagnosestellung (Ausschluss einer PDD!) ist das Geschlechtsverhältnis bei der kindlichen Schizophrenie ausgeglichen oder, vor der Pubertät (!), leicht mädchenwendig, so war das Verhältnis von männlich zu weiblich bei unseren 57 Patienten 26:31 (o.84:1). Beim Kanner'schen Autismus besteht dagegen eine typische Knabenwendigkeit (3.5-4.0:1). Beim frühkindlichen Autismus und den anderen tiefgreifenden Entwicklungsstörungen ist die prämorbide Entwicklung i.d.R. von Anfang an auffällig, während bei kindlichen Schizophrenien die vorausgehende Entwicklung entweder völlig unauffällig verläuft oder aber wesentlich weniger gravierende Beeinträchtigungen aufweist (s. Kap. 9). Auch findet sich beim frühkindlichen Autismus keine erhöhte Belastung mit Psychosen aus dem schizophrenen Formenkreis, wie dies bei der kindlichen Schizophrenie der Fall ist (Kap.12.2). Verwandte ersten Grades autistischer Kinder weisen dagegen eine höhere Belastung mit autistischen Störungen auf. Und schließlich ist ein Übergang in eine schizophrene Psychose sehr selten dies war nur bei 1 Patienten unter 163 Patienten mit einem frühkindlichen Autismus der Fall, die von Volkmar u. Cohen (1991) untersucht worden waren, das entspricht einer Häufigkeit von o,6\%, also derjenigen in der Allgemeinbevölkerung. Ein weiterer Unterschied zwischen frühkindlichem Autismus und der kindlichen Schizophrenie besteht darin, dass bei ersteren eine deutlich höhere Komorbidität mit Hirnschädigungen und mit zerebralen Anfallsleiden vorliegt (Ghaziuddin 2005). In ihrer Untersuchung über tiefgreifende Entwicklungsstörungen bei Vorschulkindern beobachteten Chakrabati und Frombonne (2005) bei knapp 67\% der Kinder mit einem frühkindlichen Autismus eine mentale Retardierung im Vergleich zu 12\% bei Kindern mit anderen tiefgreifenden Entwicklungsstörungen und o\% bei Kindern mit AspergerAutismus. 
Die genannten Befunde sprechen dafür, dass es sich beim frühkindlichen Autismus und bei der kindlichen Schizophrenie um unterschiedliche Krankheitsbilder handelt, die sich eindeutig trennen lassen. Aber es gibt auch Gemeinsamkeiten und Überschneidungen insbesondere in Bezug auf die prämorbide Frühentwicklung kindlicher Schizophrenien, welche durch sprachliche, motorische und v.a. soziale Auffälligkeiten gekennzeichnet sein kann (Alaghband-Rad et al. 1995, Ghaziuddin 2005, Schaeffer u. Ross 2002, Sporn et al. 2004) (s.a. Kap. 9).

Zur besseren diagnostischen Eingrenzung autistischer Störungen des Kindesalters wurden zwei Verfahren entwickelt: die Autism Diagnostic Observation Schedule (ADOS - Lord et al. 1999) und das Autism Diagnostic Interview-Revised (ADI-R, Lord et al. 1994). Beim ADOS handelt es sich um ein semistrukturiertes Interview mit dem Kind und seinen Eltern in einer standardisierten Spielsituation, bei dem ADI-R um ein semistrukturiertes Interview mit den Bezugspersonen. In beiden Verfahren geht es um die Evaluation des Kommunikations- und Interaktionsverhaltens sowie repetitiver und stereotyper Verhaltensmuster beim Kind. Reaven et al. (2008) prüften die Frage, ob diese Instrumente geeignet sind, zwischen autistischen und COS-Kindern eindeutig zu differenzieren und kamen zu dem Ergebnis, dass die Sensitivität und Spezifität dieser beiden Instrumente hierfür nicht ausreichte. Dies liegt eben darin begründet, dass gerade in der Vorgeschichte kindlicher Schizophrenien Störungen des Sozial- und Kommunikationsverhaltens zu beobachten sind, die denjenigen autistischer Kinder gleichen.

Der frühkindliche Autismus Kanner (F84.o) wird von Rapoport et al. (2009) zur engeren, die übrigen autistischen Syndrome (der atypische Autismus F84.1, das Rett-Syndrom F84.2, die desintegrative Störung F84.3 und der Asperger-Autismus F84.5) zur breiteren Kategorie tiefgreifender Entwicklungsstörungen (Pervasive Developmental Disorders, PDD) gerechnet. Zu letzteren gehört noch eine weitere Kategorie: die nicht näher bezeichnete tiefgreifende Entwicklungsstörung (PDD not otherwise specified, PDD-NOS). Hierbei handelt es sich um eine diagnostische Restkategorie, die für tiefgreifende Entwicklungsstörungen verwendet wird, welche nicht eindeutig die Kriterien der F84- bzw. DSM-IV-PDD- Kodierungen erfüllen.

In neuroanatomischer Hinsicht gibt es keine bzw. nur sehr geringe Überschneidungen zwischen frühkindlichen Autismus Kanner und kindlicher Schizophrenie (COS). Bei ersterem ist ein vergrößerter Kopfumfang bzw. ein vergrößertes Hirnvolumen in den ersten drei Lebensjahren zu beobachten, was mit der klinischen Symptomatologie parallel geht. Bei der COS beobachtete die Arbeitsgruppe um Rapoport einen eindrucksvollen Verlust an grauer Substanz in den ersten Lebensjahren, der sich bis in die Adoleszenz fortsetzt, im weiteren Verlauf wieder abnimmt und auf die präfrontale und die superiore Temporalregion beschränkt bleibt (Rapoport et al. 2009). Letzteres ist typischerweise auch bei erwachsenen Schizophrenen zu beobachten (s. Kap. 12.3 u. 12.4). Es scheint so, dass es beim frühkindlichen Autismus in den ersten drei Lebensjahren zu einer akzelerierten Hirnentwicklung kommt, bei der kindlichen Schizophrenie sich dieser Prozess dagegen erst im späteren Kindes- bzw. in der Frühadoleszenz (zw. 10 und 16 Jahren) abspielt. 


\subsubsection{Atypischer Autismus}

Der „atypische Autismus“ (F84.1) unterscheidet sich vom frühkindlichen Autismus Kanner durch den späteren Krankheitsbeginn (im oder nach dem 3. Lebensjahr) und dadurch, dass i.d.R. eines der für den Kanner-Autismus essentiellen Symptombereiche nicht vorhanden ist (Störung der sozialen Interaktion und Kommunikation, repetetiv-stereotypes, ritualisierendes Verhalten). Die Kinder sind meistens sehr stark intellektuell behindert und/oder leiden unter schweren umschriebenen Entwicklungsstörungen der rezeptiven Sprache. Verwandte diagnostische Begriffe sind „Intelligenzminderung mit autistischen Zügen“ und „atypische kindliche Psychose“. Die Abgrenzung zur frühkindlichen Schizophrenie ist durch das unterschiedliche Erkrankungsalter, die Intelligenzminderung und die andersartige Psychopathologie nicht schwer.

\subsubsection{Rett-Syndrom}

Dies gilt auch für das Rett-Syndrom (F84.2), welches mit einer schweren intellektuellen Behinderung einhergeht und nur bei Mädchen vorkommt. Nach normaler psychomotorischer Entwicklung kommt es nach dem 7.-8. Lebensmonat zu einer Stagnation und schließlich rasanten Verschlechterung psychomotorischer Fähigkeiten und zur Ausbildung einer Demenz mit deutlich „autistischen Zügen“. Zwischen dem 1. und 4. Lebensjahr kommt es zu einem Verlust erworbener sinnvoller Handfunktionen. Sehr charakteristisch sind Handstereotypien, „waschende Handbewegungen“, stereotypes Handreiben, stereotypes Benetzen der Finger mit Speichel, stereotypes Aneinanderlegen der Hände in Brust- oder Kinnhöhe. Typisch sind weiterhin:

- Gang-Rumpf-Ataxie,

- Anämie,

- Akinesie,

- breitbeiniges Stehen,

- Verlangsamung der allgemeinen Spontanmotorik,

- Hyperaktivität.

Kinder mit einem Rett-Syndrom bewegen ihren Kopf häufig horizontal und scheinen auf etwas in der Ferne Gerichtetes zu schauen. Wenn sie ihren eigenen Körper oder in der Nähe befindliche Objekte betrachten, tun sie es in einer seltsam verlorenen Weise, welche an das Verhalten autistischer Kinder erinnert. Die visuomotorischen Leistungen von knapp 2-jährigen Kindern mit einem Rett-Syndrom entsprechen denjenigen von zehn Monate alten gesunden Säuglingen. Pathogenetisch liegt dem RettSyndrom eine Mutation des auf dem X-Chromosom gelegenen MECP-2-Gens zugrunde („methyl-cytosine-binding-protein 2“).

\subsubsection{Desintegrative Störung}

Bei der desintegrativen Störung des Kindesalters (F84.3) verläuft die psychomotorische Entwicklung bis zum 2.-4. Lebensjahr unauffällig, danach kommt es zu einer Rückbildung erworbener Fähigkeiten mit Spiel- und Interessensverlust, schwerer Kommunikationsstörung, Sprachauffälligkeiten, motorischen Stereotypien und Manierismen, Reizbarkeit, Affektlabilität und dann affektiver Abstumpfung. Die Sprachstö- 
rungen manifestieren sich in Form von Echolalie, Phonographismus, Neologismen, Laut- und Wortvertauschungen, Wortverstümmelungen und schließlich Telegrammsprache. Es zeigt sich häufig ein sinnloser Zerstörungsdrang, manche Kinder erwecken den Eindruck, als ob sie unter akustischen und optischen Halluzinationen litten. Schließlich kommt es zum Sprachverlust und zur Ausbildung einer schweren Demenz, wobei charakteristischer Weise eine intelligent wirkende, differenzierte Physiognomie über viele Jahre hinweg erhalten bleibt („Prinzengesicht“). Das Krankheitsbild entspricht der Dementia infantilis Heller.

\subsubsection{Asperger-Autismus}

Im Gegensatz zu den bisher beschriebenen autistischen Syndromen des Kindesalters weisen Kinder mit einem Asperger-Autismus (F84.5) keine Beeinträchtigung ihrer sprachlichen Entwicklung auf, im Gegenteil der Spracherwerb erfolgt relativ früh, und die meisten Kinder entwickeln eine recht differenzierte sprachliche Ausdrucksform. Die stimmliche Modulation ist dagegen recht karg, monoton und dünn, ihre Sprechweise häufig gespreizt, manieriert, dozierend. Die motorische Entwicklung verläuft eher verzögert, die Kinder sind häufig motorisch recht ungeschickt. Die intellektuelle Entwicklung ist oft frühreif, die Begabung ist durchschnittlich oder häufig deutlich überdurchschnittlich. Früh entwickeln die Kinder besondere, oft ungewöhnliche Spezialinteressen, die sie z.T. mit regelrechter Verbissenheit verfolgen, später ergreifen sie entsprechend ausgefallene Berufe und entwickeln darin großen Ehrgeiz. Die Betroffenen sind sehr ordnungsliebend und neigen zu einer oft ins Zwanghafte gesteigerten Pedanterie. Zwangssymptome können so stark ausgeprägt sein, dass differentialdiagnostisch eine Zwangsstörung auszuschließen ist. Manche Patienten entwickeln eine Tic-Störung oder eine Anorexie.

In ihrem Kommunikationsverhalten sind die Patienten enorm eingeschränkt, sie sind äußerst kontaktunwillig oder in ihren dann zwanghaft anmutenden Kontaktbemühungen ungeschickt, distanz- und taktlos, und sie laufen daher Gefahr, zurückgewiesen zu werden. Solche Zurückweisungen werden nicht verstanden und sind Anlass für verstärkten Rückzug in eine Eigenwelt.

Schizophrene Kinder können in ihrer prämorbiden Entwicklung Asperger-ähnliche Kommunikations- und Verhaltensauffälligkeiten aufweisen (s. Kap. 9). Kinder mit einem Autismus Asperger entwickeln aber nicht häufiger eine schizophrene Psychose als die Durchschnittsbevölkerung. Die Prävalenz des Asperger-Syndroms im Schulalter liegt bei etwa 2-3/10.ooo, die Knabenwendigkeit ist noch ausgeprägter ( $80^{n}: 1$ q) als beim frühkindlichen Autismus Kanner ( $30^{\prime:}: 1$ \%).

Zur Illustration differential-diagnostischer Schwierigkeiten v.a. zu Beginn des Störungsbildes im Säuglings- und Kleinkindesalter hier ein Fallbeispiel aus der eigenen Sprechstunde, bei dem sich Symptome des Kanner'schen und Asperger'schen Autismus anfänglich durchmischen und die Differentialdiagnose erst im Schulalter gelang.

\section{Vorstellungsanlass}

Der Junge wird im Alter von 8 Jahren von seiner Mutter vorgestellt. Sie berichtet über eine starke Eigenwilligkeit und eine hohe Eigenmotivation bei ihrem Sohn. Er lasse sich bei sei- 
nen Vorhaben weder beeinflussen noch lasse er sich ablenken. Er lebe ausschließlich in einer "spinnerten“ Phantasiewelt, auf die seine Mutter sehr eingehen müsse, da es sonst zu Aggressionsdurchbrüchen komme. Es gebe Zeiten, da A. in nahezu zwanghafter Art alle Möbel und seinen Bruder berühren müsse, wenn er selbst berührt würde, müsse er die Berührung „zurückgeben“. Tue er dies nicht, gerate er schnell in einen Verzweiflungszustand. Andererseits vermeide er ebenso zwanghaft, z.B. durch Hüpfen, den Boden zu berühren, da sich das jedoch kaum vermeiden lasse, sei er an manchen Tagen sehr unglücklich und gerate in starke Unruhe- und Erregungszustände. Oder er sitze stundenlang lethargisch vor sich hinbrütend herum. Er beschäftige sich fast ausschließlich nur mit Zahlen, lebe in seiner eigenen Welt und negiere häufig Realitätsanforderungen. Z.B. esse er gelegentlich nicht, ziehe sich nicht an oder aus oder vergesse die Toilettengänge. A. bevorzuge seine Nahsinne (Berühren, Ertasten, Belecken, Beriechen).

In der Schule (1. Klasse einer KB-Schule) störe A. durch ständiges Herumlaufen und lautes Schreien. Er sei recht aggressiv zu den anderen Kindern und beteilige sich nicht am Unterrichtsstoff der Klasse. Er ziehe sich auf seine recht weit entwickelten mathematischen Fähigkeiten zurück und störe teils durch "sinnlose" stereotype Fragen. Es sei nur dem hohen emotionalen Einsatz der Klassenlehrerin zu verdanken, dass A. in der Klasse verbleiben könne. Von der Mutter werden außerdem weitere zwanghafte, stereotype Verhaltensmuster beschrieben: So sei A. beim Spiel von einem Reifen getroffen worden. Als es ihm nicht sofort gestattet worden sei, diesen Reifen nochmals zu berühren, sei er in Panik geraten. Wenn er zufällig von einem anderen Kind berührt werde, so müsse er diese Berührung sofort zurückgeben. Wenn sich eine Idee in seinem Kopf festgesetzt habe, so erfordere dies unmittelbare Befriedigung seiner Ideen und Vorstellungen, sonst gerate A. ebenfalls in Panik.

\section{Vorgeschichte}

A. ist das erste Kind der Familie. Der Schwangerschaftsverlauf war unauffällig. Die Geburt erfolgte 10 Tage nach dem errechneten Termin, wurde 2 Tage ohne Erfolg eingeleitet, es kam zur Entbindung durch die Saugglocke. Geburtsgewicht $3.900 \mathrm{~g}$, Länge 54 cm (APGAR 10).

In der Neonatalperiode fiel das Kind durch schrilles Schreien, durch eine starke Schreckhaftigkeit und Trinkschwäche auf. Das Neugeborene wurde alle 2 Stunden gefüttert. Seit der Geburt besteht eine Ptose durch Lidhebeschwäche des rechten Auges. Es bestand eine allgemeine Schlaffheit der Muskulatur (,floppy infant"). Der Säugling lag häufig in einer Opisthotonushaltung da. Wegen der Bewegungsstörung erfolgte vom 2. Lebensmonat ab bis zum 6. Lebensjahr kontinuierlich eine krankengymnastische Behandlung an der Abteilung für Risikokinder der Univ. - Kinderklinik Hamburg- Eppendorf. Der Junge lernte erst mit 16 Monaten laufen. Es bestand eine deutliche Störung des Gleichgewichtes und der Koordination.

Die Sprachentwicklung verlief sehr verlangsamt. Keine Lallmonologe, der Junge sprach mit 2,5 Jahren erst sieben Worte, danach weitere Verlangsamung der Sprachentwicklung. A. sei ein sehr ruhiges und abweisendes Baby gewesen. Er habe nie gelächelt, der Mutter nie die Arme entgegen gestreckt. Er habe nicht nach der Flasche gegriffen und sich nicht freuen können. Nach dem ersten Lebensjahr wurden autoaggressive Tendenzen deutlich. Der Junge habe viel geschrien, sich hingeworfen, mit dem Kopf gegen die Wand geschlagen oder sich mit den Fäusten selber geschlagen. Spielzeug wurde mit Ausnahme eines Kippautos nicht beachtet. Dagegen zeigte A. andauerndes Interesse an Schaltern, Hebeln, Knöpfen, die stundenlang, teils tage- und wochenlang immer wieder stereotyp hin und her bewegt wurden. A. sei nicht kontaktfähig gewesen und zeigte starke Veränderungsängste, hatte 
Angst vor jedem fremden Weg, vor Bäumen und Geschäften, es bestand eine erhebliche Licht- und Geräuschempfindlichkeit.

Im Alter zwischen 2 3/4 und 5 Jahren wurde A. im Institut für Therapie autistischer Verhaltensstörungen in Hamburg behandelt. Im Alter von 4 und 5 lahren besuchte A. den Kindergarten für Geistigbehinderte, er konnte sich nicht in die Kindergruppe integrieren und nahm keinerlei Kontakt zu anderen Kindern auf, habe weitgehend nur allein gespielt. Mit $63 / 4$ Jahren kam A. in die Vorstufe einer Körperbehinderten-Schule.

In der Untersuchungssituation verhielt sich A. zunächst freundlich, hielt kurz Blickkontakt, wandte sich dann rasch ab, verlangte Papier und Bleistift und begann intensiv zu malen und zu rechnen. Dabei war er sehr konzentriert und ausdauernd, solange er sich mit der selbst gestellten Aufgabe beschäftigte. Er saß völlig in sich gekehrt am Schreibtisch, ohne seine Umgebung wahrzunehmen. Seine Eigenmotivation war sehr hoch. Es war nicht möglich, A. zu anderen Testaufgaben zu bewegen, er zeigte eine sehr gute Durchsetzungsfähigkeit. Später wurde er motorisch unruhig, lief ziellos hin und her, er schien Personen und Gegenstände seiner Umwelt nur recht partiell aufzunehmen und weitgehend in einer eigenen Phantasiewelt zu leben, die sich aus Zahlen und Maßeinheiten zusammensetzt, von der er nur durch seine Malereien Mitteilung macht. Die verbale Mitteilungsmöglichkeit des Jungen war sehr gering. Die Einschätzung der intellektuellen Entwicklung erfolgte mit dem Progressiven Matrizen-Test (Raven) und dem Hannover-Wechsler-Intelligenztest für das Vorschulalter (HAWIVA), es ergab sich eine überdurchschnittliche Intelligenz mit einem IQ-Wert von 120, hohe Werte im rechnerischen Denken, ansonsten Leistungsschwankungen infolge mangelhafter Kooperationsbereitschaft. Es wurde eine heilpädagogische Therapie des Kindes und eine gesprächstherapeutische Beratung der Mutter empfohlen und durchgeführt.

A. bringt offensichtlich durch seine Beschäftigung mit Zahlen, Mengen- und Maßeinheiten, Berechnungen von Zeitabständen, räumlichen Entfernungen, Wärmeund Kältegraden, Tachometergeschwindigkeiten, Phonstärken etc. eine Art Ordnung in seine Welt. Seine Wahrnehmungs- und Verarbeitungsfähigkeit von Erlebnissen scheint qualitativ anders zu sein als bei anderen Kindern. Entsprechend lebt er in einer für andere unzugänglichen Eigenwelt und beschäftigt sich ausgiebig mit Spezialthemen wie Erdtiefe, Planetensysteme, Vulkanausbrüche, Flussmündungen, Schwimmbad-Hubboden, Flaggen etc.

Dies spiegelt sich auch in den Zeichnungen des damals 8-jährigen Jungen wider (s. Abb. 6).

\section{Erneute Vorstellung}

Wenige Wochen später wurde mir A. erneut vorgestellt. Die Vorstellung begann damit, dass A. zwanghaft die Mutter bedrängte, sich aufzuschreiben, dass die „Kassette“ ins Regal müsse. Die Kassette bestand aus einer Papierrolle mit einem papierartigen Überbau, auf dieser Rolle hatte A. Vierer-Reihen geschrieben.

A. malte dann einige Minuten lang jeweils Vierer-Reihen oder Verdopplungen und kam dabei bis auf eine Zahl in Milliardenhöhe. Anschließend erzählte er spontan, dass er in alle Stockwerke eines Hochhauses gehen müsse und von Wohnung zu Wohnung mit einem Stein, $30 \times 30 \mathrm{~cm}$, Leute totschlagen wolle. Dann wollte er mit einem Stein, $1 \times 1 \mathrm{~m}$, das Haus demolieren. Dies trug er in schriller Stimme vor und musste dabei sehr heftig dranghaft lachen, jedoch ohne Affekt. Schließlich erzählte er von einem Revolver, mit dem er Leute 
7.1 Frühkindlicher Autismus Kanner und andere Autismusformen, tiefgreifende Entwicklungsstörungen (PDD)
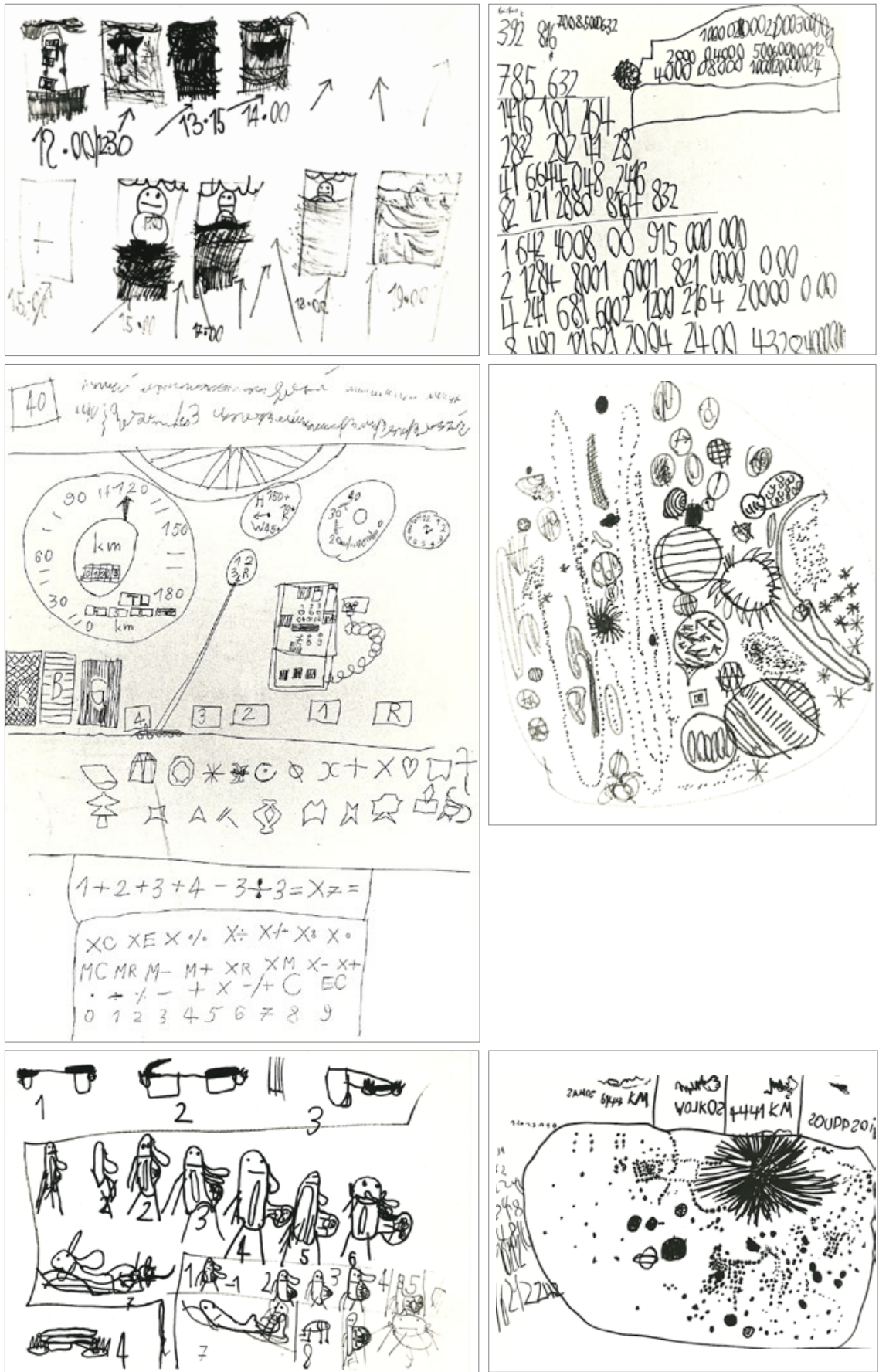

Abb. 6 Zeichnungen eines 8-jährigen Jungen mit Asperger-Autismus 
„abknallen“ wolle. Er schmückte die Geschichte bunt aus, lachte dazu und war nicht zu bremsen. „Dann mache ich noch ein Stinke-Aa dazu, ein Aa, was extra stinkt“. Auch hierbei hielt er sich minutenlang auf und war durch Fragen oder Feststellungen wie „Du musst ja eine Stinkwut haben“, überhaupt nicht zu beeinflussen.

Die Mutter berichtete, dass A. jetzt einen eigenwilligen und ebenfalls sehr sonderlingshaften „Freund" gefunden habe, mit dem und dessen Hund er durch die Gegend tolle. Ein richtiger Kontakt bestünde jedoch nicht, jeder tue eigentlich, was er wolle. Auch ziehe A. sich, wenn dieser Freund komme, gerne zurück, z.B. ins Bad, wo er Wasserspiele mache.

Die Mutter berichtete weiter, dass A. jetzt nicht mehr berührt werden wolle, selbst bei entfernter Annäherung gerate er bereits in Panik.

Ein Arzt habe Aolept verschrieben, der Junge erhalte phasenweise $3 \times 2$ Tropfen bis zu $3 \times 3$ Tropfen Aolept. A. besuche weiterhin die Körperbehindertenschule.

Eindrucksvoll ist der Bericht der Mutter über ihre früheren und jetzigen Beziehungsprobleme mit A. A. habe sie sehr stark abgelehnt und sie habe deshalb oft gedacht, „dann suche dir doch eine andere Mutter". Andererseits klebte A. an ihrem Rockzipfel, wenn sie zum Arzt ging, so dass dieser ihr Vorwürfe machte, sie verwöhne den Jungen und könne sich nicht von ihm trennen. Aber es sei doch genau umgekehrt, sie sei doch so stark von ihm abgelehnt worden. Sie habe sich zehn Jahre lang das Kind gewünscht, beide Eltern mussten sich jedoch diesen Wunsch versagen, da beide Eltern lungenkrank waren. Nach zehn Jahren habe sie den Jungen dann bekommen. Sie habe dieses Kind wegen seiner Unruhe und seinem ständigen Schreien im Wald herumgetragen und versucht es zu beruhigen. Sie habe es ganz wörtlich „unter dem Herzen getragen“ und habe es doch nicht beruhigen können, der Junge habe andauernd und fortwährend schrill geschrien, sich gegen sie gewehrt, gestrampelt und geboxt. Sie sei mit ihren Gefühlen manchmal "ganz durcheinander" gewesen. Es sei ein "Tohuwabohu“ von Gefühlen in ihr entstanden. An dieser Stelle lenke ich ein, dass es tatsächlich schwierige Kinder gebe und dass die Klischeevorstellung von falsch erziehenden Müttern eben doch sehr einseitig sei. Dabei kamen deutliche Schuldgefühle zutage, die Mutter schien recht dankbar, dass wir ihr vermittelten, dass sie ein schwieriges Kind habe und sich große Mühe gegeben habe und wirklich bis zur Grenze der Belastbarkeit gegangen sei.

Dabei kam heraus, dass die Mutter viel gelitten und sehr viel für ihr Kind getan hat. So musste der Junge früher, etwa mit 2,5-3 lahren, auf alle Bänke steigen und Treppen x-mal rauf- und runtergehen. Der Mutter kam dann in den Sinn, dass sie mit dem Kind zusammen gehe, und ganz allmählich und ganz langsam konnte sie den Jungen dazu bewegen, immer weniger oft die Treppe hinauf- und hinunterzugehen, bis es dann mit einem Mal genug war. Ähnlich verhielt es sich mit den Bänken, die auf der Strasse standen. Auch musste die Mutter dauernd singen und fröhlich sein, obwohl es "mir oft gar nicht danach zumute war", um den Jungen bei Laune zu halten und überhaupt zu ermöglichen, dass der Junge körperlichen Kontakt mit ihr aufnahm, sich ausziehen ließ usw.

Schließlich kam die Mutter auf die Idee, dem Jungen jeden Baum zu zeigen und diesen befühlen ließ, die Beschaffenheit der Rinde erklärte, besonders das Raue der Rinde erklärte, und sie merkte, dass dies den Jungen beruhigte. Beim nächsten Baum machte sie es dann wieder so. Daraufhin war es leichter, mit dem Jungen spazieren zu gehen. Die Mutter verstand, dass der Junge durch zu viel Eindrücke von außen im höchsten Maße beunruhigt war. Auch schilderte sie eindrucksvoll die Veränderungsangst. So durfte sie nur bestimmte Sachen anhaben oder dem Jungen auch nur bestimmte Sachen in bestimmten Farben anziehen mit einer bestimmten Stoffqualität, sonst geriet er in Panik. 
7.1 Frühkindlicher Autismus Kanner und andere Autismusformen, tiefgreifende Entwicklungsstörungen (PDD)

Die Mutter ist also sehr empathisch auf die Schwierigkeiten ihres Jungen eingegangen, besonders auch auf die Erschwernis, auf neue Reizgegebenheiten zu reagieren und sich auf diese einzulassen; stattdessen das stereotype Haften an Altbekannten und monotone Wiederholen des immer Gleichen!

\section{Weiterverlauf}

Im Alter von 11 Jahren wurde mir der Junge erneut vorgestellt, er besuchte jetzt die 4. Klasse einer Spezialschule für Kinder mit minimaler zerebraler Dysfunktion. Im Rechnen war er der Beste, insgesamt war er ein sehr, sehr guter Schüler, Noten nur 1 und 2. Seine Schularbeiten machte A. allein und war dabei sehr ehrgeizig. Sein Berufswunsch „RaumschiffFührer". A. ist wesentlich ruhiger, leichter führbar und umgänglicher geworden. Nach wie vor zeigt er starke Eigentendenzen, bewegt sich jetzt aber wesentlich mehr in der Realität, als noch 2 Jahre zuvor.

Mit 12 Jahren kam A. in die 5. Klasse einer Realschule. Dort war er jedoch intellektuell unterfordert und kam dann aufs Gymnasium, hatte immer sehr gute Noten. A. ist ein sehr guter Schachspieler. Er beschäftigt sich sehr viel mit seinem Computer, in Musik weiß er sehr viel. Nach wie vor bestehen starke Eigentendenzen und Schwierigkeiten, mit der Umwelt klar zu kommen und die Perspektive des Anderen einnehmen zu können.

Als er 14,5 lahre alt war schrieb die Mutter: „Zur Zeit haben wir ein sehr gutes Einvernehmen mit A. Dadurch, dass er so groß und körperlich schon recht stark geworden ist, fühlt er sich sicherer im Umgang mit seinen Mitschülern. Er wirkt gelöst, fröhlich und wird schlagfertig und witzig, so dass wir viel zusammen lachen und flachsen. Es macht Freude, ihn zu haben alle Mühe hat sich gelohnt!"

Im Alter von 20,5 Jahren machte A. Abitur mit einem Notendurchschnitt von 2,0.

Im Alter von 25 lahren stellte sich A. spontan bei mir vor und berichtete von seinen pädophilen Neigungen, er habe entsprechende Onanie-Phantasien, stelle sich dabei androgyne Jungen bzw. Mädchen vor, jeweils im Alter zwischen 8 und 10 Jahren, Jungen mit mädchenhaften Zügen und umgekehrt Mädchen mit jungenhaften Zügen. Außer einen Liebesbrief, den er vor vielen Jahren an einen Jungen geschrieben habe, sei es nicht zu aktiven Kontakten gekommen. A. hat sich zu einem sehr schlanken, sportlichen jungen Mann entwickelt, der Langstreckenlauf macht und an einer Fernuniversität Mathematik und Informatik studiert, ist also den Zahlen treu geblieben.

\subsubsection{Multiple Complex Developmental Disorder (MCDD)}

Inzwischen wurde eine weitere Kategorie einer tiefgreifenden Entwicklungsstörung herausgearbeitet, die eine nähere nosologische Verwandtschaft zur kindlichen Schizophrenie aufzuweisen scheint: die Multiple Complex Developmental Disorder, MCDD (Towbin et al. 1993). Die Störung umfasst 3 Symptombereiche:

1. Affektive Regulationsstörungen und Ängste (ungewöhnliche oder eigenartige Befürchtungen und Phobien, bizarre Angstreaktionen, wiederkehrende Panikattacken, überflutende Ängste, Episoden mit desorganisiertem, z.T. gewalttätigem Verhalten)

2. Störung des Sozialverhaltens (soziales Desinteresse, Vermeidungs- u. Rückzugsverhalten) 
3. Denkstörungen (magisches, irrationales Denken, plötzliche Gedankeneingebungen, bizarre Ideen, Neologismen, Wiederholungen von unsinnigen Wörtern, leichte Verwirrbarkeit, überwertige Ideen einschließlich Omnipotenzphantasien, paranoide Tendenzen, Eigenbeziehungen, Phantasiegefährten)

Eine spätere Weiterentwicklung der MCDD in eine schizophrene Psychose in der Adoleszenz und im Erwachsenenalter wurde beschrieben (Rapoport et al. 2009). Gegenüber Kindern mit einer PDD ist die Störung des Sozialverhaltens bei Kindern mit einer MCDD weniger stark ausgeprägt, aber letztere zeigen vermehrt Angstsymptome, stärkere disruptive Verhaltensauffälligkeiten und psychotische Züge, insbesondere Denkstörungen (DeBruin et al. 2007).

Differentialdiagnostische Schwierigkeiten bereitet die Kombination multipler psychomotorischer und sprachlicher Entwicklungsverzögerungen und Beeinträchtigungen der Affektmodulation, Kontakt- und Interaktions- sowie Denkstörungen. Diese Kinder können schizophrenieähnliche Symptome zeigen und werden als „multidimensionally impaired“ (Gordon et al. 1994, Kumra et al. 1998) bezeichnet. Sie bedürfen einer besonders sorgfältigen diagnostischen Abklärung und Abgrenzung von tiefgreifenden Entwicklungsstörungen (PDD) einerseits und frühkindlichen Schizophrenien(VEOS) andererseits, was i.d.R. nur nach einer längeren Verlaufsbeobachtung über mehrere Jahre gelingt.

\subsubsection{Lujan-Fryns-Syndrom}

Andererseits muss bei solchen Zustandsbildern differentialdiagnostisch auch an hirnorganisch bedingte Psychosyndrome gedacht werden wie z.B. das Lujan-FrynsSyndrom (DeHert et al. 1996). Es handelt sich dabei um eine X-chromosomal gebundene leichte geistige Behinderung mit marfanoiden Symptomen, welche mit psychiatrischen Symptomen einhergeht. So beobachteten Spaepen et al. (1994) bei den von ihnen beschriebenen 14 Jungen typische Symptome eines frühkindlichen Autismus $(n=4)$ bzw. einer PDD $(n=8)$, bei einem Jungen wurden akute psychotische Episoden beobachtet, was auch für andere Fallbeschreibungen mit diesem Syndrom zutrifft (Laletta et al. 1991). Der von DeHert et al. (1996) beschriebene Patient wies anamnestisch Anzeichen einer psychomotorischen Retardierung und einer leichten Lernbehinderung auf, er entwickelte im Alter von 18 Jahren das Vollbild einer paranoid-halluzinatorischen Schizophrenie, welche neuroleptisch schlecht zu behandeln war und mit fortbestehender paranoid-halluzinatorischen Symptomatik, ausgeprägten negativen Symptomen und einer starken psychosozialen Einschränkung einherging. - Der Verlauf schizophrener Psychosen bei Kindern mit einer mentalen Retardierung (IQ < 70) geht typischer Weise mit einer Verschlechterung der kognitiven Leistungsfähigkeit einher (Lee et al. 2003).

\subsection{Schizotype Persönlichkeitsstörungen}

Die Diagnose einer Persönlichkeitsstörung sollte vor Abschluss der Adoleszenz vermieden werden, da die Persönlichkeitsentwicklung bis dahin i.d.R. noch nicht zum Abschluss gekommen ist! 
Differentialdiagnostisch gegenüber der Schizophrenie entscheidend ist, dass die einer Persönlichkeitsstörung zugeschriebenen Wesensauffälligkeiten und Charaktermerkmale relativ stabil sind, wenn auch in der Pubertät und in der Adoleszenz Verhaltensschwankungen und -instabilitäten typisch und reifungspsychologisch normal sind. Keineswegs sind jedoch abgrenzbare psychotische Episoden zu beobachten wie sie bei rezidivierenden Schizophrenien vorkommen .

Schizotype Wesenszüge zeigen sich u.a. in Form von:

- eingeschränkter emotionaler Reagibilität

- affektiver Kühle

- überbetont distanziertem Verhalten

- Kontaktschwierigkeiten, Isolationstendenzen

- Hang zu exzentrischem, sonderlingshaftem Verhalten

- Neigung zu exklusiven Beziehungen

- gekünstelter, u.U. pathetischer Sprechweise

- gespreizt-manierierten, phrasenhaften Äußerungen

- ungewöhnlichen Überzeugungen

- misstrauisch-paranoiden Einstellungen

- Entfremdungserlebnissen

Wenn die genannten Symptome sehr stark ausgeprägt sind, wenn Beziehungs- und andere paranoide Wahnideen, Zwangssymptome mit aggressiven, sexuellen und dysmorphophoben Inhalten, Depersonalisations- und Derealisationserlebnisse sowie Störungen des Körpererlebens (z.B. der körperlichen Einheit), Vagheit und Umständlichkeit des Denkens und gelegentlich psychotiforme Episoden mit illusionären Verkennungen und flüchtigen Halluzinationen und Wahnideen das Symptombild bestimmen ist eine „schizotype Störung“ entsprechend ICD-10:F21 zu diagnostizieren, welche den schizophrenen Spektrumsstörungen zugerechnet wird - synonyme Bezeichnungen:

- latente Schizophrenie,

- pseudoneurotische Schizophrenie,

- pseudopsychopathische Schizophrenie,

- schizotype Persönlichkeitsstörung.

Asarnow (2005) stellte bei mehr als der Hälfte von 12 Kindern, bei denen sie eine schizotype Persönlichkeitsstörung nach DSM-III diagnostiziert hatte, noch zusätzliche Diagnosen: ADHD (50\%), Verhaltensstörung mit oppositionellem Verhalten (58\%) und depressive Störung (58\%). Dies spricht schon für die Schwierigkeit der diagnostischen Eingrenzung schizotyper Störungen im Kindesalter! Das zeigt sich auch beim Studium des Weiterverlaufs: Nach einer 3-jährigen Verlaufsbeobachtung wurde die ursprüngliche Diagnose nur bei der Hälfte der Kinder $(n=6)$ bestätigt, bei 1 Kind wurde eine Schizophrenie, bei 2 Kindern eine schizoaffektive Psychose und bei einem weiteren Kind eine „atypische bipolare Störung“ diagnostiziert (Arsanow 2005).

Abgrenzungsschwierigkeiten einer schizotypen Störung bestehen zur schizoiden und zur „emotional instabilen Persönlichkeitsstörung“ (F6o.1, F6o.31) sowie zur Schizophrenia simplex (F20.6). Eine andere Bezeichnung für „emotional instabile Persönlichkeit“ ist die sog. „Borderline-Persönlichkeit“. Hier ist wichtig, dass der Realitätsbezug bei diesen Patienten recht labil ist, dass die personalen Beziehungen oft brüchig sind, und sie zu abrupten Kontaktabbrüchen neigen, weil sie schnell frustriert und von ihren Bezugspersonen tief enttäuscht sind, wenn diese den Idealvorstellungen 
der Patienten nicht entsprechen. Es besteht eine ausgeprägte Stimmungslabilität mit starken Schwankungen ins Extreme („Himmel hoch jauchzend, zu Tode betrübt“). Pathognomonisch ist die Ich-Schwäche, was u.a. zur Folge hat, dass die Abgrenzung zwischen Phantasiewelt und Realität nicht gelingt, d.h. die „Überstiegsfähigkeit“ (Conrad) beeinträchtigt ist. Das kann sich in passageren psychotiformen wahnhafthalluzinatorischen Zuständen mit Entfremdungserlebnissen (Derealisation und Depersonalisation) und in Störungen des Ich- und Körpererlebens bis hin zu Spaltungserlebnissen äußern. Diese psychotischen Phasen sind allerdings kurzdauernd und reversibel, die Realitätsbezugsstörung erreicht nicht das Ausmaß einer veritablen Schizophrenie.

\section{Die beiden genannten Persönlichkeitsstörungen (F60.1, F60.31) sollten im Kindesalter und in der Adoleszenz nicht diagnostiziert werden!}

Die differentialdiagnostischen Abgrenzungsschwierigkeiten zwischen Schizophrenie, schizotyper Persönlichkeitsstörung, multidimensionally impaired children, multiple complex developmental disorder und tiefgreifenden Entwicklungsstörungen vom Typ Asperger sind dadurch bedingt, dass zwischen diesen Krankheitsbildern symptomatologische Überschneidungen bestehen. Tabelle 12 gibt eine Übersicht über die diagnostischen Merkmale der genannten Störungen entsprechend DSM-IV-TR (APA 2000, TR = Text Revision) wider (Carlson u. Fish 2005, p. 72).

Der Zusammenhang zwischen schizothymen (E. Kretschmer 1955) bzw. seelisch-asthenischen (K. Schneider 1943) Wesenszügen und einer Neigung zu Derealisations- und Depersonalisationserlebnissen, z.T. mit Mikro- und Makropsien wird in der folgenden Fallgeschichte deutlich. Die bei der Nachuntersuchung zu beobachtende Persönlichkeitsstörung weist starke Anklänge einer schizotypischen Persönlichkeitsstörung auf, entspricht aber nicht dem Vollbild einer F21-Störung.

\section{Auffällige Familienanamnese}

Die Großmutter väterlicherseits litt an rezidivierenden schizoaffektiven Psychosen, ihr Bruder suizidierte sich.

Der prämorbid ängstlich-selbstunsichere Junge, guter Schüler, interessiert, litt im Alter von 8 lahren an plötzlich auftretenden Angstzuständen, Kontaktverlust und Schlaflosigkeit. Er schrie: „Mutti, die Welt geht unter, wo bist du denn? Die Welt wird dunkel, es ist alles kleiner, ich sehe dich ja gar nicht mehr richtig". An den folgenden Tagen wollte er von anderen Kindern nichts wissen und nicht zur Schule gehen, schlief schlecht. Nach vier Tagen erneut Angstzustände: „Mutti, es geht wieder los, wo bin ich denn, es wird alles kleiner ... alles ist ganz klein ... ich glaube ich werde, ich werde nie mehr gesund ... ich glaube, ihr müsst mich in eine Anstalt bringen“. "Hilfe, Hilfe, wo bin ich, das Bett fährt weg, jetzt sind wir ganz tief unten in der Erde drin“. Ein anderes Mal sagte er: „Es ist, als ob es ganz von alleine spräche, als ob ich gar nicht selbst spräche“.

Während der 11-wöchigen Klinikbeobachtung war der Junge kontaktfähig, zugewandt, unbeschwert, jedoch traten 2mal Angstzustände auf (er schrie völlig unvermittelt voller Angst, sagte hinterher dazu, es sei "alles anders" gewesen, „das Bett sei schief“ gewesen, es sei, „als ob das Bett mit ihm nach rechts davonfahre"). 
Neurologischer Befund, Liquorbefund und Pneumenzephalographie unauffällig, IQ (HAWIK): 110.

\section{Nachuntersuchung:}

Bei der Nachuntersuchung im Alter von 17 lahren wirkte der Patient etwas unschlüssig, wenig spontan, überlegte lange, bevor er antwortete, wirkte ernst, feinfühlig, differenziert, nach außen hin kühl, innerlich aber angespannt und nervös. Nach der Entlassung habe er die Volks- und Mittelschule mit guten Zeugnissen abgeschlossen und anschließend eine 4-jährige Schlosserlehre absolviert mit dem Ziel, den Ingenieurberuf zu ergreifen.

Die Angstzustände hätten an Häufigkeit und Intensität nachgelassen. Besonders schlimm sei es im Alter von 8-9 Jahren gewesen („irgendwie rückte alles von mir ab, ich fühlte mich so eingeengt", „es kam einfach, dass ich schrie"). Seine Entfremdungserlebnisse schilderte er mit den Worten „plötzlich war alles so ganz unwirklich, irgendwas war, was mich entrückt hatte, so dass ich mir etwas anders vorkam". Das letzte Mal habe er vor einem halben Jahr solch einen Zustand gehabt. Manchmal komme es zu kurzdauernden grundlosen Verstimmungen („alles unheimlich traurig“). Seine Gefühle zu den Menschen seien „irgendwie verblasst“, „zu einer richtigen tiefen Zuneigung kann ich gar nicht mehr kommen“. Das sei so allmählich gekommen. Früher sei er teilnahmefähiger, seine Gefühle herzlicher und inniger gewesen. Jetzt habe er „keine echten Gefühle“ mehr zu anderen Menschen, er stelle sich dabei vor, dass er das "gar nicht mehr braucht", das er ganz für sich allein sein könne. Auch den Eltern gegenüber empfindet er "keine richtige tiefe Zuneigung", bei seiner Freundin sei es ähnlich, manchmal sei „,diese Gleichgültigkeit“ für kurze Zeit weg, einen Anlass dafür gebe es nicht, „das kommt dann einfach so, ich stelle mich einfach darauf ein, gleichgültig und unbeteiligt zu sein". Er habe keinen richtigen Freund, jedoch Bekannte, der Kontakt zu innen sei jedoch oberflächlich. Auf die Frage, ohne was er nicht leben könne, antwortete er: „Gar nichts", er könne „ganz für sich allein leben“.

\subsection{Zwangsstörungen}

Es besteht kein Zweifel, dass Zwangssymptome im Verlauf schizophrener Psychosen vorkommen und sogar über weite Strecken bildbeherrschend sein können (vgl. Kap. 4.4 u. 5.2.3). Auch können sie recht bizarrer Natur sein, so dass eine differentialdiagnostische Abgrenzung von psychotischen, insbesondere Wahnsymptomen schwierig sein kann.

Zwischen Zwang und Wahn gibt es einen qualitativen Unterschied: Beim Zwang ist die Reflexionsfähigkeit erhalten, der Patient erkennt die Unsinnigkeit seiner Gedanken, Vorstellungen, Impulse und Handlungen und wehrt sich gegen die entsprechenden Bewusstseinsinhalte. Für den Wahn ist dagegen die Unkorrigierbarkeit und Unbeeinflussbarkeit durch Argumente anderer kennzeichnend.

K. Jaspers (1959, S. 112f.) unterscheidet zwischen Zwangsaffekten (als fremdartig empfundene Gefühle, gegen die sich der Betroffene erfolglos wehrt), Geltungszwang (Zwang, etwas für wahr bzw. richtig halten zu müssen, dessen Unmöglichkeit zugleich eingesehen wird) und Zwangsimpulsen bzw. -handlungen, die als unsinnig und dem Wesen nicht entsprechend angesehen werden. 


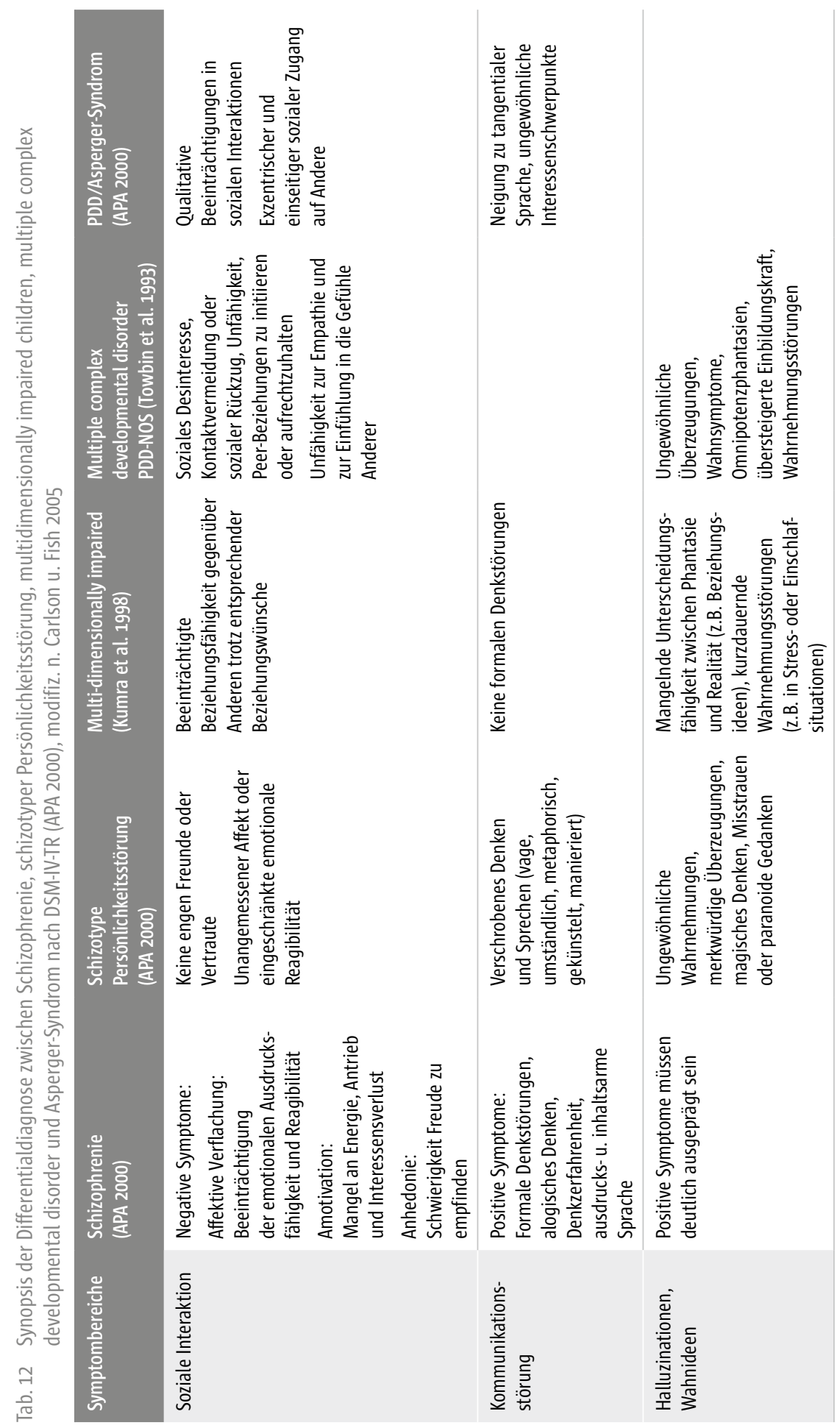




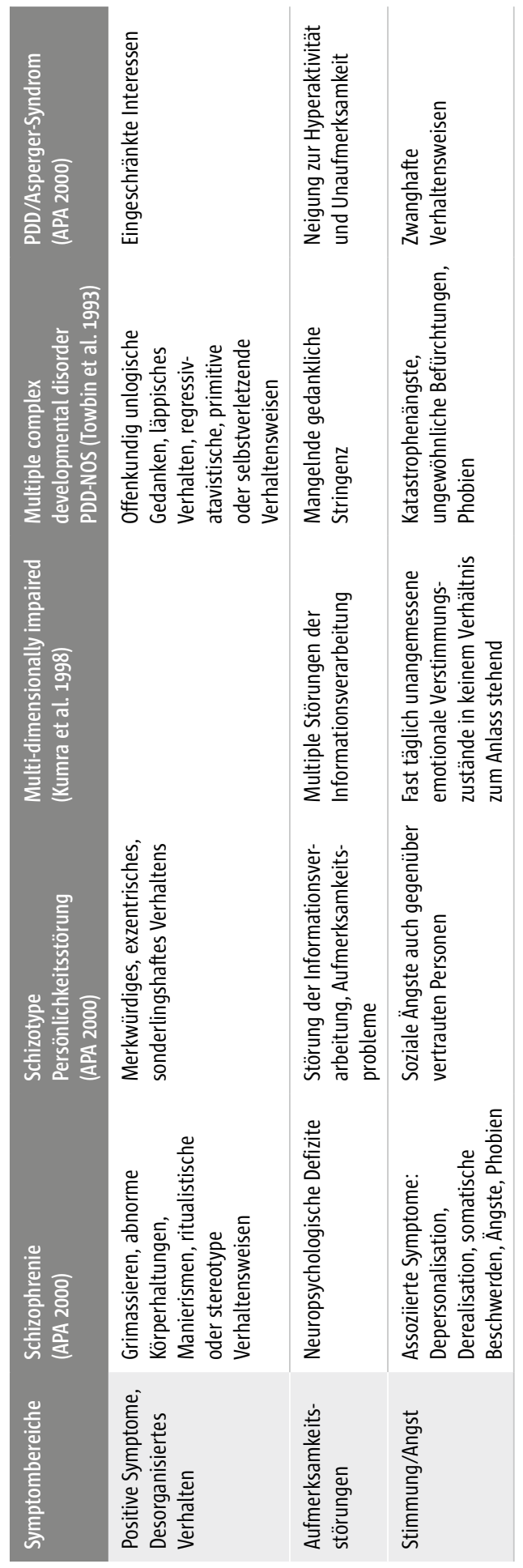


Zwangsaffekte manifestieren sich i.d.R. als Zwangsbefürchtungen, z.B. an unheilbaren Krankheiten zu leiden, sterben zu müssen, vergiftet zu werden etc. Hier ist die differentialtypologische Abgrenzung von Wahnideen zwingend, wobei das differenzierende Kriterium die Unkorrigierbarkeit des Wahns ist - im Gegensatz zur Zwangsvorstellung bzw. -befürchtung, welche als widersinnig und als im Gegensatz zu eigenen Vorstellungen stehend erkannt werden, von denen die Betroffenen aber nicht loskommen können. Wie in einem Kampf gegen Windmühlen drängen sich die Zwangsvorstellungen und -befürchtungen immer wieder gegen den eigenen Willen auf.

In neuerer Zeit wird versucht, durch neuroradiologische Untersuchungen (MRT, fMRT) Gemeinsamkeiten und Unterschiede zwischen Zwangsstörungen und Schizophrenie herauszuarbeiten. So konnten Kwon et al. (2003) bei 22 schizophrenen und 22 Zwangs-Patienten im Vergleich zu 22 Gesunden magnetresonanztomographisch bilaterale Volumenreduzierungen beider Hippocampi feststellen, jedoch war bei den Zwangspatienten im Gegensatz zu den schizophrenen Probanden das Volumen der linken Amygdala vergrößert. Die Amygdala haben eine große Bedeutung für Emotionen, insbesondere für Angst und Furcht, welche bei der Zwangskrankheit pathogenetisch eine wichtige Rolle spielen.

In Bezug auf die Thalamusaußenfläche konnten Kang et al. (2008) Unterschiede zwischen schizophrenen und Zwangspatienten feststellen: Während Zwangspatienten Deformitäten in der anterior-lateralen Region des rechten Thalamus und der hinteren Portion des hinteren linken Thalamus aufwiesen, bestand bei den schizophrenen Patienten eine Oberflächendeformität der dorso-medialen Portion des linken Thalamus und der postero-lateralen Portion des rechten Thalamus. Der medio-dorsale Thalamuskern hat enge neurale Verknüpfungen mit dem dorsolateral-präfrontalen Cortex (DLPFC), der eine zentrale Bedeutung für exekutive Funktionen und Aufmerksamkeitsprozesse hat, die bei schizophrenen Patienten beeinträchtigt sind. Dagegen sind der anteriore und ventrale laterale Thalamuskerne involviert bei der Unterdrückung unerwünschten und ungewollten Verhaltens. Diese Hemmfunktionen sind wiederum bei Zwangspatienten beeinträchtigt. Es scheint also so zu sein, dass unterschiedliche neuroanatomische Veränderungen der verschiedenen Thalamuskerne bei der Pathogenese der Zwangskrankheit einerseits und der Schizophrenie andererseits beteiligt sind.

\subsection{Körperlich begründbare Psychosen}

Jede im Kindes- oder Jugendalter neu auftretende schizophrene Psychose muss dringend differentialdiagnostisch auf das Vorliegen einer körperlichen Grunderkrankung hin untersucht werden, und zwar nicht nur einmal sondern u.U. mehrmals im Frühverlauf weil z.B. ein Hirntumor im Anfangsstadium leicht übersehen werden kann!

Kinder und Jugendliche mit psychotischen Symptomen müssen sorgfältig pädiatrisch und neurologisch untersucht werden, inklusive EEG, EKG, bildgebende Verfahren wie Magnetresonanztomographie (MRT), Blutbildkontrolle und Drogen-Screening. 
Durch eine körperliche Erkrankung hervorgerufene Psychosen werden als „körperlich begründbare Psychosen“ (K. Schneider 1947) bezeichnet. Weitgehend synonym hiermit werden folgende Termini verwandt: „akute exogene Reaktionstypen“ (Bonhoeffer), „symptomatologische Psychosen“ (Gruhle), „Geistesstörungen im engen Zusammenhang mit Körperkrankheiten“ (E. Bleuler). Es hat sich jedoch eingebürgert, kurz von „organischen“, „symptomatischen“ oder „exogenen“ Psychosen zu sprechen. Durch die erwähnten Begriffe soll zum Ausdruck gebracht werden, dass die damit bezeichneten Psychosen - im Unterschied zu den endogenen Psychosen auf eine direkte oder indirekte Hirnerkrankung zurückzuführen sind. Diese Psychosen könnten nicht vorkommen ohne eine hirnorganische Bedingtheit, die für ihr Auftreten unerlässlich ist, wenn sie auch nicht ausschließlich für deren Genese und Phänomenologie verantwortlich ist (Huber 1972).

Da wir heute sehr viel mehr über organische, d.h. neuro- und molekularbiologische Bedingtheiten sogenannter endogener Psychosen - in erster Linie schizophrener und affektiver Psychosen - wissen, ist diese Unterscheidung zumindest fragwürdig geworden. Gleichwohl sind bei den körperlich begründbaren (exogenen) Psychosen die jeweils auslösenden Noxen wie u.a. internistische und neurologische Erkrankungen, Schädel-Hirntraumen, Intoxikationen etc. als wesentliche ursächliche Grundbedingungen anzusehen.

Neben der organischen Schädigung sind andere Faktoren am Entstehen sowie an der phänomenologischen Ausgestaltung der Psychosen beteiligt. Dazu gehören individualtypische Determinanten, die für das Zustandekommen und die Ausprägung einer exogenen Psychose von Bedeutung sind:

n die prämorbide Persönlichkeitsartung,

- das Lebensalter,

- das jeweils erreichte psychophysische Reifungs- und Entwicklungsniveau des Kindes,

- die Stoffwechsellage,

- Leber- und Nierenfunktion (deren Intaktheit besonders bei Intoxikationen wichtig ist) und

- situative Gegebenheiten, insbesondere die Art der familiären Verankerung und Beschützung.

Die zuletzt genannten Einflüsse schränken die pathoklitische Spezifiät exogen-psychotischer Zustandsbilder ein. Deren phänomenologische Variabilität wird durch die Heterogenität der erwähnten Bedingtheiten mitbestimmt.

Der ätiologische Einfluss bzw. die pathogenetische Bedeutung der den exogenen Psychosen des Kindesalters zugrundeliegenden Noxen hängt jeweils von deren schädigenden Potenz ab.

Körperlich begründbare Psychosen sind ebenso wie schizophrene Psychosen durch Störungen der Wahrnehmung, des Denkablaufes, des Antriebs, der Stimmung und der emotionalen Steuerung gekennzeichnet. Die Wahrnehmungsstörungen zeigen sich in optischen, akustischen, selten auch olfaktorischen oder gustatorischen Sinnestäuschungen. Das Denken kann inkohärent bis zerfahren oder delirant-verworren sein. Der Antrieb ist reduziert, von der Apathie bis zum Stupor, oder gesteigert bis zur katatonen Erregung. Die Emotionalität ist so gut wie immer verändert, entweder freudig-euphorisch-maniform oder depressiv-herabgedrückt, moros, reizbar, quen- 
gelig oder hochgradig angstvoll-verzweifelt, gepeinigt. Auch hier sind flukturierendwechselnde Übergänge im zeitlichen Verlauf möglich.

Im Gegensatz zur Schizophrenie, die häufig multiepisodisch-rezidivierend oder schleichend-progredient verläuft, sind die psychotischen Phänomene bei den exogenen Psychosen auf die Dauer der Einwirkung der Noxe (z.B. bei einer Intoxikation) bzw. eines somatischen Krankheitsprozesses (z.B. Fieberdelir im Rahmen eines fieberhaften Infektes) beschränkt. Aber es gibt auch Ausnahmen wie z.B. bei drogeninduzierten Psychosen, einer Temporallappenepilepsie oder bei manchen Vergiftungen wie z.B. Kohlenmonoxyd-Vergiftungen. So wurde von K. Schneider (1947) ein Patient beschrieben, der wiederholt von ihm untersucht und dessen Krankheitsbild als Schizophrenie eingestuft worden war. Erst autoptisch gelang die Zuordnung zur Kohlenmonoxyd-Vergiftung. Es hatten sich ausgedehnte Zerstörungsherde im Frontal- und Okzipitalbereich, eine beidseitige Ammonshornsklerose und symmetrische Ausfälle im Pallidum gezeigt, ein Befund, der die Bedeutung limbischer, insbesondere amygdalo-pallido-striärer Faserverbindungen und deren Funktionen für die Genese halluzinatorisch- wahnhafter Phänomene unterstreicht (vgl. Kap. 12.3).

Andererseits kann die psychotische Symptomatologie gelegentlich der körperlichneurologischen Symptomatik vorausgehen, wie dies z.B. bei der Subakuten Sklerosierenden Panenzephalitis oder bei manchen Hirntumoren, selten einmal auch bei systemischen Bluterkrankungen (Anämien, Leukosen) vorkommen kann. Gerade die psychopathologische Symptomatologie zu Beginn einer Subakuten Sklerosierenden Panenzephalitis (SSPE) ähnelt sehr prämorbiden und prodomalen Erscheinungsweisen kindlicher Schizophrenien: Knickhaft einsetzende Wesensänderung mit desinteressiert-teilnahmslosem oder aggressivem Verhalten, Unkonzentriertheit und nachlassenden Schulleistungen. Fokale oder generalisierte Krampfanfälle, Gleichgewichtsstörungen und eine generalisierte Steigerung des Muskeltonus sowie plötzlicher Tonusverlust mit Stolpern und Fallneigung sind neurologische Frühsymptome, die auf eine neurologische Genese der Psychopathologie hinweisen. Im weiteren Verlauf hinzukommende rhythmische extrapyramidal-motorische Hyperkinesien sowie typische Myoklonien oder 1 bis 3 Sekunden dauernde atonische oder tonische Anfälle, die mit entsprechenden charakteristischen EEG-Veränderungen korrelieren (sog. Radermecker-Komplexe), verweisen auf die Diagnose einer SSPE. Radermecker-Komplexe sind periodische, in Abständen von 3,5-12 Sek. repetitiv auftretende hochvoltige slow-wave Komplexe. Im weiteren Verlauf kommt es zu einer allmählich fortschreitenden Dezerebrierung mit Sprachzerfall, intellektuellem Abbau, affektiv-emotionaler Verarmung, Kontaktabbruch, akinetischem Mutismus, ungezielten Erregungen mit Schreiattacken („cris encéphaliques“), Rigor, Spasmen, Tetraspastik, Erblindung und Entwicklung eines apallischen Syndroms mit schließlich letalem Ausgang nach monate- bis jahrelangem Verlauf. Bei der SSPE handelt es sich um eine chronisch-progredient verlaufende, durch eine persistierende Maserninfektion hervorgerufene entzündliche Erkrankung des ZNS.

Häufig gehen exogen verursachte Psychosen mit deliranten Symptomen und einer Bewusstseinstrübung einher (z.B. Fieberdelir). Wenn eine solche vorliegt, ist die differentialdiagnostische Abgrenzung zur Schizophrenie relativ leicht, obwohl bei Kindern auch „endogene“ schizophrene Störungen v.a. im Akutstadium mit Verwirrtheitszuständen, räumlicher und zeitlicher Desorientiertheit, Ratlosigkeit und mnestischen Störungen einhergehen können, also mit Symptomen, die an sich ty- 
pisch für hirnorganisch bedingte Psychosen sind. Andererseits fehlen gerade bei Kleinkindern Bewusstseinsstörungen nicht selten auch bei bedrohlichen körperlichen Grunderkrankungen (Eggers 1975), und selbst schwere Schädel-Hirn-Traumen hinterlassen in dieser Altersphase häufig keine bleibenden Persönlichkeitsveränderungen oder Intelligenzeinbußen (Lange-Cosack u. Tepfner 1973).

Eine fehlende Bewusstseinstörung und das Fehlen eines zurückbleibenden hirnorganischen Psychosyndroms (Adynamie, Umständlichkeit, Denk- und Konzentrationsstörungen, Gedächtnisstörungen, psychomotorische Verlangsamung, Reizlabilität, Affektinkontinenz) können die Abgrenzung zwischen kindlichen Schizophrenien und exogenen, körperlich begründeten Psychosen schwierig gestalten. Jedoch ist die psychopathologische Symptomatologie bei den somatogenen Psychosen im Kindesalter bewegter und farbiger als bei den schizophrenen Psychosen des Kindesalters. Die exogen bedingten Halluzinationen stehen in der Regel realen Wahrnehmungen sehr viel näher, als dies bei endogenen Störungen der Fall ist. Sie sind häufig lebhaft, farbig, bewegt und bunt. Den halluzinierten Gestalten fehlt im allgemeinen das Befremdliche, Uneinfühlbare, Neuartige, das die Halluzinationen schizophrener Kinder kennzeichnet, wenn sie z.B. das „Welttelefon“ an der Zimmerdecke oder einen „Riesen aus Rauch sich um den Apfel ringeln und den Menschen in die Münder kriechen" sehen. Auch die Wahnerlebnisse sind bei exogenen Psychosen alltäglicher, banaler, „welthafter“. Exogen psychotische Kinder sehen bevorzugt Tiere, aber auch Menschen aus ihrer gewöhnlichen Umgebung. Nicht selten bestehen Beziehungen zwischen den halluzinierten oder phantasierten Inhalten und (Fernseh-)Filmen, die die Kinder kurz zuvor gesehen haben, oder anderen rezenten Ereignissen, wie beispielsweise dem Besuch eines Zoos.

Bemerkenswert ist, dass exogene Psychosen so gut wie nie das Bild einer Hebephrenie oder einer Dementia simplex imitieren. Zeigt eine frühkindliche Psychose (insbesondere vor dem 6./7. Lebensjahr) ein buntes Erscheinungsbild und ähnelt es phänomenologisch einer akuten Erwachsenenschizophrenie, so handelt es sich eher um eine exogene Psychose, auch wenn Bewusstseinstrübungen oder delirante Symptome fehlen.

Als Sondertyp kindlicher exogener Psychosen, die durch ihre Flüchtigkeit leicht von kindlichen Schizophrenien abzugrenzen ist, wurde von uns die sog. akute optische Halluzinose des Kindesalters beschrieben (Eggers 1975). Sie ist durch das Hervortreten optischer gegenüber anderen Sinnestäuschungen und durch das Fehlen von deliranten Symptomen und Bewusstseinstrübungen gekennzeichnet. Die Stimmung ist entweder hochgradig ängstlich oder aber freudig-euphorisch erregt, wobei das gesamte Ausdrucksverhalten des betroffenen Kindes völlig dieser gesteigerten Emotionalität entspricht. Die Halluzinosen pflegen innerhalb weniger Stunden bis Tage folgenlos abzuheilen, ohne bleibende körperliche oder psychopathogenetische Residualsymptome zu hinterlassen.

Exogene Psychosen des Kindesalters können als Folge einer ganzen Reihe von pädiatrischen, internistischen und neurologischen Erkrankungen auftreten (s. Tab. 13).

Beim Kind treten flüchtige exogene Psychosen häufig im Rahmen hochfieberhafter Infekte auf als Fieberhalluzinosen oder als flüchtige delirante Zustände.

So halluzinierte ein $5^{1 / 2}$-jähriger Junge, der an einem hochfieberhaften Infekt mit Temperaturen um $40^{\circ}$ erkrankt war, lebhaft optisch (Schlangen, Frösche, Hasen, 
Tab. 13 Somatische Ursachen exogener Psychosen des Kindesalters

\begin{tabular}{ll} 
Neurologische Erkrankungen & Pädiatrisch-internistische Erkrankungen \\
\hline Schädel-Hirn-Traumen & Allgemeininfektionen \\
\hline Meningo-Enzephalitiden & Viruserkrankungen (z.B. Masern, Mumps) \\
\hline Enzephalotoxikosen & Metabolische und endokrinologische Erkrankungen \\
\hline Neurometabolische Hirnerkrankungen & Hepato- u. Nephropathien \\
\hline Heredodegenerative Abbauprozesse & Intoxikationen \\
\hline Hirntumore & Neoplasien \\
\hline & Postoperative Krisen, insbes. nach Herzoperationen \\
\hline & Hypoxämische Zustände bei kardio-vaskulären Erkrankungen \\
\hline
\end{tabular}

Schiffe, Ringe, Bälle). Er sah diese Dinge auf seinem Bett und zeigte mit der Hand darauf. Außerdem hörte er Stimmen (z.B. von Nachbarskindern), mit denen er sich unterhielt. An der Wand sah er eine nicht vorhandene Uhr, las von ihr die Zeit ab, sah Frösche auf dem Boden herumhopsen und äußerte u.a. „da springen Männer hoch wie Porsche“, wobei er auf das Fenster wies. Die Stimmung des Buben war ängstlich-erregt, das Bewusstsein war nicht getrübt. Am Tag darauf (Temperatur $38^{\circ}$ ) sagte der Junge: „Jetzt ist alles weg.“

Ähnliche Erscheinungsbilder können auch als Prodromalerscheinungen oder im Verlauf spezifischer Viruserkrankungen wie Masern oder Mumps auftreten, ohne dass eine begleitende Meningoenzephalitis nachweisbar ist. Akute reversible exogene Psychosen können bei endokrinen Störungen, wie bei der Hyperthyreose, beim Morbus Addison oder beim Hyperparathyreoidismus intermittierend-episodenhaft in Erscheinung treten; durch eine entsprechende Substitutionstherapie können sie wieder beseitigt werden.

Psychotische Episoden und autistische Symptome sind auch bei Störungen des Aminosäurenstoffwechsels beschrieben worden, wie z.B. bei der Phenylketonurie oder bei der Histidinämie. Auch bei Lipidosen sind vereinzelt psychotiforme Syndrome beobachtet worden, u.a. halluzinatorische und expansiv-manische Zustände bei der sog. amaurotischen Idiotie. Weinschenk (1976) berichtete über eine schubweise verlaufende paranoid-halluzinatorische Psychose mit intermittierenden depressiven und manischen Verstimmungen bei einem 15-jährigem Knaben mit einem Morbus Gaucher.

Typisch für das Kindesalter ist, dass in dieser Altersphase eine ganze Anzahl verschiedener Substanzen und Substanzgruppen exogene halluzinatorische Symptome hervorrufen können, und zwar nicht nur im eigentlichen Sinne psychotomimetisch wirksame Substanzen sondern auch unspezifische Pharmaka wie Analgetika oder antiinfektiös wirksame Mittel, Substanzen, die bei Erwachsenen nur in seltenen Ausnahmefällen analoge Symptome hervorrufen würden. Hierfür zwei Beispiele:

Ein 3 Jahre alter Junge hat drei Stunden nach Einnahme von 10 Dragées Tantum (= 500 mg Benzydamin), einem entzündungshemmend, analgetisch und antiödematös wirksamen Medikament, eine akute optische Halluzinose entwickelt. Das prämorbid gemüthafte, phan- 
tasiebegabte und tierliebe Kind geriet in einen hochgradigen Erregungszustand mit starker Angst. Es schrie: „Ich bin von einer Schlange gebissen“, „da ist ein Krokodil“; „bringt die Tiere weg“, „da ist Blut“. Das Kind versuchte, die Tiere, die es halluzinierte, tot zu treten oder sich durch heftige Abwehrbewegungen vor ihnen zu schützen. Die äußerst starke motorische Unruhe mit choreatiformen Bewegungen hatte paroxysmalen Charakter, wobei die Intervalle zwischen den „Anfällen“ sehr kurz waren (Sekunden bis Minuten). Der Junge halluzinierte weiterhin „Schlangen, Krokodile, Elefanten und Hunde“, die ihn beißen wollten und sah Blut an sich selbst, an der Mutter und am Arztkittel. Das Bewusstsein war erhalten; der Junge war voll orientiert und antwortete adäquat auf Fragen. Nach etwa 12 Stunden war der Junge wieder unauffällig, die Stimmung war jedoch deutlich gehoben, heiter; der Junge war logorrhoisch, freundlich, zugewandt und lebhaft. - Erwähnenswert ist, dass der 3-jährige Junge einen Tag vor der Erkrankung einen Zoo besucht und abends im Fernsehen einen Tierfilm (Daktari) gesehen hatte.

Ein 4\%2-jähriger Junge, dem vom Hausarzt wegen Erbrechens Paspertin-Saft (Metoclopramid) in einer Dosis von $3 \times 5 \mathrm{mg}$ verschrieben worden war, entwickelte ein extrapyramidal-dystones Syndrom mit Torticollis, Opisthotonushaltung, extrapyramidalen Hyperkinesien beider Oberarme, verkrampfter Handstellung und anfallsartigen Seit- und Rückwärtsbewegungen des Oberkörpers. Die Symptomatik verschwand nach Gabe von 1 Ampulle Akineton (Biperiden) i.v. völlig. 2 Stunden später traten jedoch optische Halluzinationen sowie Makropsien bei erhaltenem Bewusstsein auf. Der Junge sah plötzlich eine Sonne, einen Hubschrauber, ein Auto, dem ein Rad fehlte, eine Hexe, rote Schnecken an der Decke und auf dem Fußboden, tote Vögel und einen „kaputten Sessel“ in der Ecke stehen; er sah u.a. Blätter und Zigaretten im Bett liegen sowie „Knallfrösche“ und einen Pilz auf dem weißen Handtuch. Zur Schwester sagte der Junge: „Mensch, bist du aber groß“. Plötzlich schrie er: „Da kommt schon wieder so ein Ding, die haben sich ja maskiert, und was für große Zehen die haben“. Der Junge war dabei stark ängstlich, zwischendurch aber freudig erregt, er lachte hin und wieder und fragte dabei, woher die „Dinger“ denn kämen. Er war stets voll bewusstseinsklar und orientiert; er nannte seinen Namen, sein Alter, seinen Herkunftsort. Er benannte Dinge korrekt, unterhielt sich, wenn er nicht zu stark von seinen Halluzinationen abgelenkt war, sinnvoll und flüssig, z.B. über sein Spielzeug und über seine bevorzugten Spiele. Die Halluzinose klang nach etwa 12 Stunden allmählich ab, nach 20 Stunden halluzinierte der Junge nicht mehr.

Tabelle 14 enthält eine Übersicht über Substanzgruppen, die bei Kindern zu exogenen Psychosen führen können.

Alle die in Tabelle 15 aufgelisteten viralen Meningo-Enzephalitiden können potentiell im Prodromalstadium mit halluzinatorischen und/oder deliranten Zustandsbildern einhergehen, wobei zu den deliranten Symptomen Bewusstseinsstörungen verschiedener Schweregrade gehören. Die klinischen Begleitsymptome (Fieber, Appetitlosigkeit, Übelkeit, Erbrechen, Abgeschlagenheit, Kopfschmerzen, Benommenheit) weisen auf eine infektiöse Genese hin. Bei der Herpes-Simplex-Enzephalitis kann es nach der Prodromalphase, etwa 4-6 Tage nach Erkrankungsbeginn, zu einem psychotischen Durchgangsstadium mit unspezifischen psychischen Auffälligkeiten und schließlich Halluzinationen, illusionären Verkennungen, Verwirrtheit, Geruchsmissempfindungen und aphasischen Symptomen kommen, welche aber mit Fieber und Meningismus einhergehen und zur Verdachtsdiagnose einer Herpes-Enzephalitis führen müssen, v.a. wenn dann zusätzlich fokale und/oder generalisierte Krampfanfälle hinzukommen! Spätestens zu Beginn dieses Stadiums, also wenn nach einem als grippaler Infekt imponierenden Zustands- 
Tab. 14 Substanzgruppen mit möglichen psychischen Nebenwirkungen

\begin{tabular}{ll}
\hline Belladonnaalkaloide & Anthelminthika \\
\hline Antihistaminika & Analgetika \\
\hline Anticholinergika & Tranquilizer \\
\hline Psychotomimetika & Antipsychotika (Neuroleptika u. Antidepressiva) \\
\hline Hypnotika u. Narkosemittel & Organische Lösungsmittel \\
\hline Sedativa u. Antikonvulsiva & Digitalisalkaloide \\
\hline Quecksilber u. Quecksilberalkyle & Zystostatika \\
\hline Brom, Blei, Thallium & Stimulanzien \\
\hline Kohlenmonoxid & Giftige Pilze \\
\hline
\end{tabular}

Tab. 15 Virale Entzündungen des ZNS

\begin{tabular}{ll} 
Virus & Krankheitsbezeichnung \\
\hline Herpes-Virus & Herpesenzephalitis \\
\hline Adeno-Virus & Subakute Enzephalitis \\
\hline Arbo-Virus & Frühsommermeningoenzephalitis (FSME) \\
\hline Paramyxo-Virus & Mumps-, Masernenzephalitis \\
\hline Rubella-Virus & Progressive Rubellapanenzephalitis („slow virus infection“) \\
\hline
\end{tabular}

bild eine plötzliche Verhaltensänderung auftritt - „das Kind verhält sich so merkwürdig“ müssen eine EEG- und MRT-Untersuchung durchgeführt und eine antivirale Therapie mit Aciclovir eingeleitet werden! Das EEC zeigt eine allgemeine Verlangsamung und/oder temporale Herde mit Spitzenpotentialen, das MRT Entzündungsherde temporo-basal.

Auch im Verlauf einer durch das Epstein-Barr-Virus hervorgerufenen Meningoenzephalitis im Rahmen eines Pfeiffer'schen Drüsenfiebers (infektiöse Mononukleose), welche typischerweise Jugendliche und junge Erwachsene befällt, kann es neben Kopfschmerzen, Bewusstseinsstörungen und einer Lichtempfindlichkeit zu plötzlichen Verhaltensänderungen mit halluzinatorischen Symptomen kommen!

Die durch Zecken übertragene Frühsommermeningoenzephalitis (FSME) weist in etwa 4\% der Fälle zu Beginn ein psychotiformes Bild auf mit vorwiegend depressiven Symptomen. Bei ca. 2/3 der Erkrankten kommt es nach einer Inkubationszeit von 7-12 Tagen im Rahmen einer Virämie zu sehr hohen Fieber und Magen- Darmerscheinungen. Nach einem beschwerdefreien Intervall von 2-5 Tagen tritt erneut hohes Fieber auf mit Kopfschmerzen, Lichtscheu und Übelkeit, in 50-70\% der Fälle kommt es zu einer Meningitis, bei ca. 30\% zu einer Meningo-Enzephalitis mit Bewusstseinsstörungen bis hin zum Koma, extrapyramidalmotorischen Symptomen und Krampfanfällen. Die ZNS-Symptomatik bildet sich im günstigsten Fall rasch nach wenigen Tagen zurück, kann aber auch noch wochenlang andauern. Die Sicherung der Diagnose erfolgt im Frühstadium durch den direkten Erregernachweis im Blut, eventuell auch aus dem Liquor. 
Typhuserkrankungen können mit akuten exogenen Psychosen schizophreniformer oder hypomanischer Prägung sowie mit deliranten Zuständen einhergehen. Auch bei einer akuten Niereninsuffizienz können flüchtige schizophreniforme, paranoid-halluzinatorische Psychosen vorkommen.

Nach einer Mumpserkrankung traten bei einem 9,3-jährigen Jungen Angst- und Erregungszustände mit optischen Halluzinationen auf (,eine Reihe von Händen fahren vor meinen Augen her“, er sah sich und die Kameraden beim Fußballspiel, ,jetzt kommen sie, die Hände, ich sehe Fußballer“, er sah einen großen Zahn, der sich vor seinen Augen hin und her bewegte, und 2 große Greifer, die „Korn zwischen sich gequetscht“ und zwischen die er hineingefallen sei). Nach wenigen Tagen wieder unauffällig, voll remittiert entlassen.

\section{Nachuntersuchung im Alter von 19 Jahren}

In der Zwischenzeit nie wieder erkrankt. Der Jugendliche wirkte geistig beweglich, voller Schwung, seine Grundstimmung war heiter, ausgeglichen. Er schilderte sich als gesellig, habe viele Freunde und zahlreiche Hobbies (Sport, Skat, Stammtisch). Im Kontaktverhalten war er freundlich, höflich, zugewandt, erschien teilnahmefähig, gutmütig-humorvoll, offenherzig, aufgeschlossen, lebens- und realitätsnah. Der junge Mann nimmt das Leben von der guten Seite, schildert sich als Optimist, er lasse sich nicht so leicht aus der Ruhe bringen und habe Freude am Beruf, sei praktisch veranlagt und verfüge über ein gutes Selbstvertrauen.

Bei älteren Schulkindern und Jugendlichen mit dem Erscheinungsbild einer schizophrenen Psychose sind eine detaillierte Drogenanamnese sowie ein Drogenscreening anzuraten. Denn drogeninduzierte Psychosen sind im akuten Stadium phänomenologisch nicht von einer Schizophrenie zu unterscheiden. Bildbeherrschend sind optische und akustische Halluzinationen, psychomotorische Unruhe- und Erregungszustände, motorische Getriebenheit, Angst und Panik, paranoide Wahnsymptome, vegetative Begleiterscheinungen wie Tachykardie, Blutdruckirregularitäten, Schwitzen, Störungen der Pupillenmotorik.

Cannabis-Psychosen sind durch Stimmungssteigerung oder dysphorische Verstimmungen, formale Denkstörungen, panische Angstzustände, paranoide Wahnideen, illusionäre Verkennungen und Sinnestäuschungen gekennzeichnet, es kann typischerweise zu Horror-Trips und Flash-Back-Zuständen (sog. Nachhallpsychosen) kommen. Es gibt Hinweise darauf, dass die psychotomimetischen Effekte des Cannabis dopaminerg vermittelt werden, wofür auch Untersuchungen an Ratten sprechen, die belegen, dass Cannabinoide die Dopaminfreisetztung im N. accumbens fördern (s. Kap. 12.12). Cannabis setzt aber eine ganze Kaskade von Veränderungen im Neurotransmittersystem frei. So regulieren Cannabisrezeptoren neben Dopamin auch die Freisetzung u.a. von GABA, Glutamat und Serotonin, welche für die Genese schizophrener Psychosen von großer Bedeutung sind. Die psychotropen Effekte des Cannabis werden hauptsächlich durch den Einfluss des $\Delta 9$-Tetrahydrocannabinols ( $\Delta 9$-THC) auf spezifische neurale Cannaboidrezeptoren vermittelt. Während das $\Delta 9$-Tetrahydrocannabinol im Wesentlichen für die psychotomimetischen Wirkungen des Cannabis verantwortlich ist (D'Souza et al. 2004), verfügt eine andere Cannabiskomponente, das Cannabidiol (CBD), über anxiolytische und antipsychotische Eigenschaften. Beide Substanzen sind in Haaranalysen nachweisbar. Inzwischen setzt sich mehr und mehr der Gebrauch einer besonders potenten Form von Cannabis durch (Skunk). 
Skunk enthält etwa 12-18\% des psychotomimetisch wirksamen THC und nur 1,5\% des antipsychotisch wirksamen Cannabidiol. Dadurch ist die Wahrscheinlichkeit, eine schizophreniforme Psychose zu entwickeln etwa um das 7-fache erhöht (Di Forti et al. 2009).

Neben den beschriebenen vegetativen Symptomen sind buntfarbige optisch-szenische Halluzinationen typisch für Halluzinogene wie LSD und Meskalin; außerdem eine breite Palette psychotischer Symptome wie Depersonalisations- und Derealisationsphänomene, Veränderungen des Raum-Zeiterlebens, Halluzinationen, Wahnideen, Angst- und Panikattacken, depressive Stimmungen und Suizidimpulse im Verbund mit Horror- und Flash-Back-Zuständen.

Kennzeichnend für Amphetamin-Psychosen sind wahnhafte Beziehungs- und Verfolgungsideen, optische und akustische Halluzinationen, Veränderungen des Körpererlebens und eine gesteigerte motorische Hyperaktivität mit Stereotypien sowie kardio-vaskuläre Symptome wie Tachykardie, Arrhythmie, Hypertonie und erhöhte Atemfrequenz.

Ein buntes psychopathologisches Bild mit akustischen, optischen, haptischen und Geschmackshalluzinationen, Entfremdungserlebnissen, Störungen des Ich- und des Raum- und Zeiterlebens, gelockerten Assoziationen, Denkzerfahrenheit, Angst- und Panikzuständen, Suizidideen, aber auch abnormen Glücks- und Omnipotenzgefühlen sind charakteristisch für durch Phencyclidin (PCP, „angel dust“) ausgelöste Psychosen.

Inhalationen von Schnüffelstoffen führen zu neurologischen Begleiterscheinungen wie Ataxie, Dysarthrie und Nystagmus sowie zu einer Pupillenerweiterung (Mydriasis). Psychopathologisch kommt es zu deliranten Zuständen mit Bewusstseinsstörungen, starker psychomotorischer Unruhe, illusionären Verkennungen, Halluzinationen und Wahnideen.

Ein 16-jähriger Junge fiel durch häufige Zustände von „Geistesabwesenheit mit starrem Blick“
auf. Er fürchtete, umgebracht zu werden, litt unter Verfolgungsideen, akustischen, optischen
und haptischen Halluzinationen und abnormen Körpersensationen („,es ist als ob der Körper
beengt wäre, als ob ich in einer Papierrolle drinstecken würde und nicht atmen könnte.") Er
sah einen Mörder vor sich stehen und fürchtete von ihm, umgebracht zu werden. Des Wei-
teren berichtete er über Beeinflussungserlebnisse, er könne seine psychotischen Erlebnisse
nur loswerden, „,wenn derjenige will“. An seinem Hals fühlte er Finger bzw. eine Hand, die
ihn berührten. Nach knapp 3 Wochen kam es zur Spontanremission.

\section{Prämorbide Entwicklung}

Zunächst ein guter Schüler, kam es im Alter von 9-10 Jahren zu einem Leistungsabfall, zu Erziehungsschwierigkeiten, Davonlaufen, Herumstreunen, Angstzuständen und Misstrauen. Mit 14 lahren Weglaufen mit gestohlenem Geld und Schmuck, Gelddiebstähle, Handel mit Morphium, deshalb 4 Wochen Jugendgefängnis. Der Junge stammte aus einfachen Verhältnissen, der Vater wurde als streng geschildert. Keine Auffälligkeiten in der Familienanamnese.

\section{Nachuntersuchung}

Bei der Nachuntersuchung im Alter von 31 Jahren gab der Patient an, dass er vor dem Klinikaufenthalt an „Benzinsucht“ gelitten habe, er habe damals in einer chemisch-pharmazeuti- 
schen Fabrik gearbeitet, es sei zum "Rausch“ gekommen, er habe dabei „Halluzinationen“ gehabt. Seitdem sei er nie wieder psychotisch gewesen.

\begin{abstract}
Der Patient gab sich ungeniert, weltmännisch-augenzwinkernd, wirkte sehr selbstbewusst, war stets höflich und zugewandt. Er redete fast ununterbrochen, erzählte ausführlich und umständlich, neigte dabei zum Protzen und Aufschneiden. Emotional wirkte er flach, ohne gemüthaften Tiefgang. Er bot das Bild eines kalten Egoisten, nur auf seinen Vorteil bedacht, auch bereit, Delikte zu begehen, z.B. Diebstähle, wenn er sich dadurch bereichern könnte, er würde sich vorher aber "ausrechnen, ob es sich lohnt“. Er sei sich des Unrechts zwar bewusst, lasse es aber außer acht, wenn er Profit davon habe, auch wenn ein Armer betroffen würde. Er selbst bezeichnete sich als willenstark, draufgängerisch, skrupellos, zu Stimmungsschwankungen neigend, er sei jähzornig. Er schlug einmal kurzerhand einen Hund tot, der sein Kind leicht gebissen hatte. Er stellte sich als unbeherrscht, explosiv dar, vergesse sich leicht, er sei als Schläger bekannt und schlage auch seine Frau. Er betrachte seine Frau vorwiegend als Sexualpartner, der außerdem den Haushalt zu versorgen habe. Sich selbst gestatte er eine „Hausfreundin“. Mit seinen Kindern verfahre er gutmütig oder auch grob, wie es ihm passe. Im Beruf zeigte er Initiative, Schwung, Ehrgeiz, Fleiß und Ausdauer, hatte es bis zum Ortsältesten im Bergbau gebracht, besuchte gleichzeitig eine Bergbauschule um Steiger zu werden. Er zeigte Sinn für Humor, und erwies sich als schlagfertig, als einer, der das Herz „auf dem rechten Fleck hat". Sich selbst bezeichnete er nicht als krank, und meinte, man hätte inn „in eine Erziehungsanstalt tun müssen, da hätte ich hingehört". Seit dem Alter von 24 Jahren sei er verheiratet, seitdem kam es zu einer allmählichen Stabilisierung in seinem Leben.
\end{abstract}

\title{
Epileptische Psychosen
}

Epileptische Psychosen treten meistens im Zusammenhang mit komplexen fokalen (partiellen) Anfällen auf, im EEG sind typischerweise fokale Herdbefunde in der Temporalregion zu registrieren. Diese Psychosen sind durch akustische, olfaktorische und gustatorische Halluzinationen, Bewusstseinstrübungen und Desorientiertheit gekennzeichnet. Während der dem eigentlichen Anfall vorausgehenden Aura können neben der Bewusstseinstrübung („Umdämmerung“) Halluzinationen auftreten, die umso vielfältiger sind, je älter das Kind ist: bei jüngeren Kindern stehen coenästhetische Sensationen im Vordergrund („,komisches Leibgefühl, Engegefühl im Hals- und Brustbereich“), später kommen auch optische, akustische, gustatorische und v.a. olfaktorische Halluzinationen hinzu. Typisch sind auch Déjà-vu- und Déjà-vécu-Erlebnisse, traumhaft-oneiroide-Zustände (,dreamy-states“), wie sie meisterhaft von Mörike in seiner Novelle „Mozart auf der Reise nach Prag“ beschrieben worden sind!

Die Symptome dieser Epilepsieform („psychomotorische Epilepsie“), insbesondere Halluzinationen und Dreamy-states, verweisen auf das limbische System als neuralen Ausgangsort der psychomotorischen Epilepsie. Die psychoseähnlichen Phänomene haben nicht nur symptomatologisch, sondern sicher auch ätiopathogenetisch eine Nähe zu schizophrenen Psychosen, die ebenfalls mit limbischen Dysfunktionen verknüpft sind (Eggers 1981).

Bei einem nachfolgend beschriebenen Patienten musste die ursprüngliche Diagnose „kindliche Schizophrenie“ aufgrund der katamnestischen Erhebung revidiert werden. Die halluzinatorischen und produktiv-psychotischen Episoden mit Erregungsund motorischen Unruhezuständen erwiesen sich retrospektiv als epileptische Äqui- 
valente bei einer Temporallappen-Epilepsie. Bei dem Patienten hatten sich schließlich eine epileptische Wesensänderung mit auffälligen Störungen der Affektivität und eine ausgeprägte Neigung zu oft gefährlichen dissozialen Handlungen herausgebildet. In letzter Zeit traten immer wieder schwere episodische Verstimmungen und Verhaltensauffälligkeiten mit teilweise brutalen Aggressionen zutage, die als produktiv-psychotische Dämmerzustände aufzufassen waren. Als Kleinkind hatte der Patient bereits generalisierte Anfälle mit Bewusstseinsverlust und „Schaum vor dem Mund " gehabt, wie katamnestisch vom Vater zu erfahren war. Elektroencephalographisch war ein epileptogener Fokus links temporal nachweisbar. Die Ursache der Temporallappen-Epilepsie dürften die vom Vater katamnestisch beschriebenen cerebralen Anfälle im Kleinkindesalter bilden, die nach Untersuchungen von Scholz (1951) sowie von Corsellis (1970) und Falconer (1971) zu pathologisch-anatomischen Schäden des Temporallappens führen können.

Der prämorbid als kontaktschwacher Einzelgänger geschilderte Junge war folgsam, willig und durchschnittlich begabt. Mit etwa 11 Jahren fielen Verhaltensstörungen auf: Geistesabwesenheit in der Schule, schlechte Schulleistungen, Mangel an Ausdauer, völlig unmotiviertes Verlassen der Schule, häufiges Weglaufen, Herumtreiben, kleine Diebstähle. Der Junge zog sich immer mehr zurück und hörte zeitweise imperative Stimmen, die ihm allerhand zuflüsterten („tu'das“, „nimm das“, „, das darfst du nicht machen “). Während des Klinikaufenthaltes im Alter von 11 Jahren war er zunächst ruhig und unauffällig, zwischendurch aber immer wieder ungezogen, eigensinnig, herausfordernd und frech. Zeitweise geriet er in starke Erregungszustände mit gefährlichen Aggressionen, in denen er völlig unbeeinflussbar war und einmal auf 4 Pfleger gleichzeitig einschlug und sie trat, so dass sie ihn kaum bändigen konnten. Unmittelbar nach einem weiteren Erregungszustand gab der Junge an, dass er eine Stimme gehört habe, die ihm befohlen habe, aus dem Fenster zu springen. - Ein Pfleger hatte inn daran gehindert, worauf es zu der Erregung kam.

In der Folgezeit kam es wiederholt zu Erregungszuständen, der Junge berichtete häufiger von akustischen Halluzinationen imperativen Charakters. Die katamnestischen Erhebungen ergaben, dass der Junge später fast ununterbrochen insgesamt 7 lahre in einem Psychiatrischen Krankenhaus gewesen ist. Dort war das Verhalten ebenfalls wechselnd, Zeiten relativer Angepasstheit und Unauffälligkeit wechselten ab mit Zeiten, wo er rüpelhaft, frech und aufsässig war, er unternahm dann immer wieder Fluchtversuche mit Diebstählen und Aggressionen. Auffallend waren Selbstbeschädigungen des Patienten, er verschluckte u.a. Drahtstücke und Teile einer Stahlrahmeneinlage seines Bettes, so dass zweimal eine Magenoperation notwendig war. Zwischendurch war der Patient monatelang entlassungs-und arbeitsfähig. Seit 1962 kam es etwa alle 2-3 Monate zu sinnlosem Weglaufen, Diebstählen und starkem Alkoholgenuss, insbesondere bei Mondwechsel. Wenn er "seine Zeiten“ hatte, meist einen Tag vor dem Mondwechsel, war "mit ihm nichts mehr anzufangen“; er war dann nervös und unruhig und auffallend blass. An solchen Tagen war er immer besonders gefährdet, versuchte sich Geld zu beschaffen, lief von zu Hause und von der Arbeitsstelle fort und fing an zu trinken. Zwischenzeitig war er jedoch ein tüchtiger, fleißiger und zuverlässiger Arbeiter und gemütswarmer, tierlieber Mensch. 1965 trat eine Verschlechterung ein, der inzwischen 22-jährige Patient tötete sinnlos Tiere, schlug seine Schwester bewusstlos, streunte umher, trank viel, verübte unmotivierte Einbruchdiebstähle und nächtigte wochenlang im Wald, er war oft „wie ein gefährliches Raubtier“ (Angaben des Vaters). Begründungen für sein Verhalten konnte der Patient nie angeben, er habe sich nie etwas dabei gedacht 
und seine teils kriminellen Handlungen nie vorbereitet. Im Oktober 1965 hatte er nachts einen Stallhasen getötet, am Gartenzaun aufgehängt und anschließend einen Einbruchsdiebstahl begangen, um sich Spirituosen zu besorgen - ohne Vorsichtsmaßnahmen und so vernunftswidrig, dass er auf frischer Tat ertappt worden war. Später gab der Patient an, dass er den Hasen habe streicheln wollen und inn erst getötet habe, als dieser geschrien habe. Er selbst habe „Blut sehen wollen“. Wegen dieses Delikts erfolgte eine Begutachtung auf seine strafrechtliche Verantwortlichkeit hin. Dabei zeigte der Patient weder formale noch inhaltliche Denkstörungen, und es waren keinerlei Zeichen einer affektiven Verödung noch sonstige schizophrene Persönlichkeitszüge nachweisbar. Ein abgeleitetes EEG zeigte nach wie vor einen epileptogenen Fokus temporal links. Seit dieser Zeit befindet sich der Patient dauernd in stationärer psychiatrischer Behandlung.

Im Verlauf einer Epilepsie können episodische Psychosen auftreten, die nosologisch zum Formenkreis der exogenen (somatogenen) Psychosen gehören. Das Bewusstsein ist in der Regel erhalten oder nur leicht getrübt; die Symptomatologie ist schizophrenieform (Wahnvorstellungen, Halluzinationen, Entfremdungserlebnisse). Das EEC ist normal. Psychosen können sich auch im Rahmen einer „forcierten Normalisierung“ (Landolt 1963) manifestieren, unter der antiepileptischen Medikation kommt es hierbei zu einer Normalisierung des pathologischen EEGs und gleichzeitig zum Auftreten der „Alternativpsychose“ mit produktiv-psychotischen und affektiv-ängstlichen Symptomen.

Über die Beziehungen zwischen Schizophrenie bzw. schizophrenieähnlichen Psychosen und Epilepsie gibt es in der traditionellen psychopathologischen Literatur zahlreiche Abhandlungen (Übersicht bei Prüter und Pohlmann-Eden 2002). Die Koinzidenz ist zumindest z.T. durch eine gemeinsame entwicklungsneurobiologische Vulnerabilität bedingt, insbesondere durch neuroanatomische Veränderungen im Bereich medialer Strukturen des Temporallappens (Amygdala, Hippocampus, Parahippocampus).

Iktale Psychosen manifestieren sich als zeitlich begrenzte, nur Stunden oder Tage andauernde schizophrenieforme Zustände mit bunten halluzinatorischen Bildern, Wahnsymptomen und formalen Denkstörungen. Die Mehrzahl der iktalen Psychosen geht mit einem Herdbefund in der Temporalregion einher, etwa ein Drittel der Patienten weisen einen extratemporalen Herd auf, in der Regel im Cingulum oder in der Frontalregion (Sachdev 1998).

Postiktale Psychosen treten meistens bei Patienten auf, die jahrelang, häufig mehr als 1o Jahre, an sekundär generalisierenden komplexen Partialanfällen leiden. Ätiologisch dürften funktionelle oder anatomische Veränderungen im Bereich des Temporallappens, z.B. hippocampale oder amygdaloidale Sklerosen, eine Rolle spielen (Kanemoto et al. 1996, Umbricht et al. 1995).

\section{Exkurs: Entwicklungspsychologische Hypothesen für die Genese exogen- psychotischer Phänomene im Kindesalter}

Das kindliche Gehirn ist offensichtlich anfälliger für Noxen, die bei Erwachsenen keine psychotomimetischen Auswirkungen haben. Dies dürfte auf der somatischen Ebene in der mangelnden Ausreifung neuraler Strukturen des kindlichen ZNS begründet sein. Auf der psychologischen Ebene sind es Bedingungsfaktoren wie Stimmung, 
Emotionalität, Antrieb, Eidetik, Vigilanz und Aufmerksamkeit, welche an der Genese psychotischer Phänomene wie z.B. optische Halluzinationen entscheidend beteiligt sind.

Diese Faktoren sind nicht isoliert voneinander zu betrachten, sondern sie hängen eng miteinander zusammen. So spricht man von „Allgegenwart des Gefühls“(Krueger 1953) in der menschlichen Person und sieht in ihm das zentrierende, integrierende, alle Bereiche und Schichten verflechtende Moment (Vetter). Die Affektivität spielt in einer früheren Lebensphase, nämlich zur Zeit des physiognomisch-animistischen Weltbildes des Klein- und jungen Schulkindes sogar eine sehr dominierende Rolle (Werner 1959) und drängt z.B. die rationale Realitätskontrolle zurück.

Dass unter dem Druck starker Affekte (Angst, Erwartung, Wünsche) illusionäre Umdeutungen real vorhandener Gegenstände der Umgebung vorkommen können, ist jedem bekannt. Auch entspricht es allgemeiner Erfahrung, dass unter dem Einfluss von Stimmungen wie Freude, Trauer oder einer gesteigerten affektiven Erregung die Umgebung des Menschen auch beim Erwachsenen Züge wesenhaften Ausdrucks erhält, d.h. man wird durch die Außenwelt auf dem Boden der Gefühlsdynamik physiognomisch-ausdrucksmäßig angesprochen, gepackt, in Bann gezogen, wie sonst nur vom personalen Ausdruck. Die Affektlage hat somit einen wichtigen Anteil am Wahrnehmungserleben insbesondere der Wesens- und Ausdruckseigenschaften eines Wahrnehmungsgegenstandes und spielt bei der Genese optischer Sinnestäuschungen eine Rolle.

Nun beeinflussen nicht nur die emotionale Einstellung und Gestimmtheit des Wahrnehmenden den Wahrnehmungsvorgang, sondern auch umgekehrt hat das Wahrgenommene Wirkungen auf die Emotionalität selbst. Diese Wirkungen machen einen gewichtigen Teil dessen aus, was Tellenbach (1968) als das „Atmosphärische“ beschrieben und in seiner anthropologischen Bedeutung diskutiert hat. Er hat es folgendermaßen definiert:

„In nahezu jeder Erfahrung unserer Sinne findet sich ein Mehr, das unausgedrückt bleibt. Dieses Mehr, das über das Reale, Faktische hinaus liegt, das wir aber in eines damit spüren, können wir das Atmosphärische nennen (S. 47).“

Am Beispiel der Dostojewski-Figur des Iwan Karamasoff hat Tellenbach (1968) aufgezeigt, wie es durch „Atmosphärisierung des Daseins“ zu einer kritischen Abwandlung in eine Halluzinose kommen kann.

In Goethe’s Gedicht „Erlkönig“ wird deutlich, wie sehr beim Kleinkind das affektive dynamische Zentrum den Wahrnehmungsvorgang beeinflusst, und nicht von ungefähr ist es in der Sage vom Erlkönig ein Kind, dashalluziniert, das „so bang“ sein Gesicht verbirgt. Die unheimliche Umgebung des schwarzen Moors mit dem gespenstig aussehenden Gestrüpp und dem schleirigen Nebel sind mitauslösend für die Angst des kleinen Jungen, den der Vater nicht beruhigen kann. Die hochgradig ängstlich-erregte Stimmung bereitet den Boden für die wahnhaft-illusionäre, phantasiehafte Verkennung und Umdeutung der Umgebung.

Über ähnlich wahnhafte Bedrohtheitserlebnisse unter dem Einfluss einer situationsgebundenen ängstlichen Erregung, die in einer fremden und auf das Kind unheimlich wirkenden Umgebung entstanden war, berichtet Bella Chagall in ihren Kindheitserinnerungen („Brennende Lichter“). Über ihren ersten Besuch als kleines Kind im 
rituellen Bad erzählte sie, wie sie auf den Ruf einer alten Badefrau: „koscher“ zusammenschreckte:

„Ich zucke zusammen, wie vom Donner gerührt, stehe bebend da und warte. Gleich wird von den schwarzen Balken der Decke ein Blitz niederfahren und uns alle töten. Oder aus der steinernen Wand werden sich Fluten ergießen und uns alle ertränken."

Das Kindheitserlebnis von Bella Chagall spiegelt ebenso wie die Ballade vom Erlkönig die „urtümliche dynamisierte und physiognomisierte Anschauungsweise“ (Werner) des Kindes wider, die in hohem Maße vom Gefühl bestimmt ist. Dass die Wahrnehmungswelt des Kleinkindes eine „Welt des Ausdrucks, eine physiognomische Welt“(Werner)ist, geht Hand in Hand mit einem Mangel an Differenzierung. Dabei treten u.a. die Unterschiede zwischen Vorstellung und Wahrnehmung noch weitgehend zurück, wodurch in dieser Altersphase leichter Phänomene auftreten, die dem Erwachsenen als illusionäre Verkennungen oder gar als Tugendwahrnehmungen imponieren.

Nun treten körperlich begründbare Psychosen nicht nur bei Klein- und jungen Schulkindern sondern auch bei älteren Kindern auf, also in einer Alterphase, in der eine rational-kritische Weltbetrachtung immer mehr an Boden gewinnt, wobei die dingliche Umwelt den Ausdruckscharakter verliert zu Gunsten einer allmählichen Versachlichung und Desillusionierung des Weltbildes. Es ist zu vermuten, dass es hier durch exogene Einflüsse wie Fieber, Pharmaka, Allgemeininfektionen und Entzündungen im Bereich des Zentralnervensystems und die dadurch hervorgerufenen neurophysiologischen und neurochemischen Veränderungen zu einer Entdifferenzierung zwischen Wahrnehmung und Vorstellung, zwischen objektivem und subjektivem Erleben, und zu einem Überwiegen des gefühlshaft-subjektiven Erlebens kommt.

Diese Verwischung von Wahrnehmungs- und Vorstellungswirklichkeit, wobei die Vorstellung mehr Wahrnehmungscharakter gewinnt als es der rational-kritischen Weltbetrachtung des älteren Schulkindes gemeinhin entspricht, ist für die Neigung zur Ausbildung halluzinatorischer Erlebnisse mitverantwortlich.

Emotionale Spannungszustände mit gesteigerten affektiven Reaktionsbereitschaften, insbesondere wenn sie durch eine Abschwächung externer Stimuli (Dämmerung, Dunkelheit) und die dadurch bedingte Versunkenheit und intensivere Zuwendung zur unmittelbaren Umgebung unterstützt werden, können beim Kind halluzinatorisch-illusionäre Erlebnisse fördern. Das sei anhand einer Selbstschilderung von Friedrich Hebbel verdeutlicht, die die visionär gesteigerte Einbildungskraft und Erlebnisfähigkeit des jungen Friedrich Hebbel anschaulich wiedergibt (Tagebücher 1885-1887):

„Schon in frühster Zeit war die Phantasie außerordentlich stark in mir. Wenn ich des Abends zu Bett gebracht wurde, so fingen die Balken über mir zu kriechen an, aus allen Ecken und Winkeln des Zimmers glotzten Fratzengesichter hervor und das Vertrauteste, ein Stock, auf dem ich selbst zu reiten pflegte, der Tischfuß, ja die eigenen Bettdecke mit ihren Blumen und Figuren wurden mir fremd und jagten mir Schrecken ein."

Aus diesem Selbstbericht geht nicht hervor, ob es sich bei dem Geschilderten um leibhaftig Erlebtes oder eher um Subjektiv-Vorgestelltes, also um Halluzinationen oder um Pseudo-Halluzinationen handelt. Die Unterscheidung zwischen Wahrnehmungsund Vorstellungscharakter optischer Phänomene ist im Kindesalter verständlicher- 
weise schwierig, was mit dem zu diesem Zeitpunkt noch wenig entwickelten Abstraktions- und Differenzierungsvermögen des Kindes zusammenhängen dürfte.

\subsection{Akute vorübergehende psychotische Störungen}

Im Gegensatz zur Schizophrenie handelt es sich bei den akuten vorübergehenden psychotischen Störungen um akute, kurzdauernde, rezidivierende Psychosen mit günstiger Prognose. Sie sind selten, genaue Häufigkeitsangaben für das Kindesalter gibt es nicht. Das Krankheitsbild wird in der ICD-10 unter F 23 verschlüsselt. Die psychotische Symptomatik setzt akut innerhalb eines Zeitraums von zwei Wochen oder weniger ein. Das psychopathologische Zustandsbild ist unterschiedlich und wechselhaft (,polymorph“). Nicht selten geht der psychotischen Episode ein aktuelles psychosozial belastendes Ereignis voraus (Liebesenttäuschung, Verlust eines nahen Angehörigen, Trennung oder Scheidung vom Partner).

In der französischen Literatur sind diese Krankheitsbilder als „bouffées délirantes aigues" beschrieben. Es handelt sich dabei um flüchtige, aus „heiterem Himmel“ akut auftretende wahnhaft-halluzinatorische Störungen mit starken affektiven und psychomotorischen Erregungszuständen, die nach wenigen Tagen wieder abklingen. Meist sind die Kinder hochgradig ängstlich erregt, emotional aufgewühlt und antriebsgesteigert. Ratlosigkeit und/oder Verkennungen von Personen und Orten sind ebenfalls zu beobachten.

\section{Fallbeispiel}

\section{Aszendenz}

Der Großvater mütterlicherseits litt an Depressionen, eine Cousine väterlicherseits als Kind unter Angstzuständen und Somnambulismus.

Familiensituation

Vater gefallen, der Stiefvater, von Beruf Lehrer, wurde als nervös, unbeherrscht beschrieben, die Mutter als autoritär, die ihre Familie mit ihren Launen unter Druck setzte. Es gab viel Streit und Spannungen zwischen den Eltern.

\section{Vorgeschichte}

Der Junge war jedes Jahr etwa 14 Tage lang bedrückt, unkonzentriert und antriebsarm.

\section{Prämorbid}

Sehr guter Schüler, gut kontaktfähig, heiter, fröhlich.

Erkrankungsbeginn: Plötzlich

Erkrankungsalter: 11 jahre

\section{Psychopathologisches Bild}

Konzentrationsstörungen, Angstzustände, traurige Verstimmung, optische und Geruchshalluzinationen, Vergiftungsideen, abnorme Körpersensationen („Gefühl, als ob Rauch durch den Körper ziehe“). Nach wenigen Tagen Abklingen der Symptome.

Therapie: Keine 


\section{Nachuntersuchung}

Alter des Patienten 24 lahre. Nachbeobachtungszeit 13 Jahre. Der Patient ist in der Zwischenzeit nicht wieder erkrankt. Nach der Erkrankung sei er noch eine Zeitlang misstrauisch gewesen, mit der Zeit habe er sich aber eine „dickes Fell“ zugelegt. Abitur und Studium der Medizin, zzt. 6. Semester. Der Patient erschien freundlich, höflich, machte einen warmherzigen, gutmütigen, differenzierten und sensiblen Eindruck. Er sei beliebt, hilfsbereit, etwas scheu und zurückhaltend, aber kontaktfähig. Keinerlei Persönlichkeitsauffälligkeiten.

Das beschrieben Krankheitsbild ist als ,akute polymorphe psychotische Störung ohne Symptome einer Schizophrenie“ (F 23.0) einzuordnen.

Wenn zusätzlich schizophrene Symptome entsprechend F 20.0 - F 20.3 ständig vorhanden sind, ist das Krankheitsbild unter F 23.1 als „akute polymorphe Störung mit Symptomen einer Schizophrenie“ zu verschlüsseln. Die schizophrene Symptomatik dauert nicht länger als einen Monat an. Es sollte mindestens eins der Symptome von F $20 \mathrm{C}$ 1.1a-G 1.2c nachweisbar sein:

- formale Denkstörungen wie Gedankenlautwerden,

- Gedankeneingebung,

- Gedankenentzug oder Gedankenausbreitung,

- Kontrollwahn,

- Beeinflussungsideen,

- Gefühl des Gemachten,

- kommentierende oder dialogische Stimmen,

- bizarre Größenideen,

- Halluzinationen verschiedener Sinnesmodalitäten,

- Neologismen,

- Gedankenabreißen,

- Denkzerfahrenheit,

- katatone Symptome,

- Negativismus,

- Mutismus,

- Stupor.

\section{Fallbeispiel}

\section{Aszendenz}

Schwester des Vaters mehrfach in stationärer Behandlung wegen paranoider Schizophrenie mit Denkzerfahrenheit und stuporös-katatonen Zuständen.

Familiensituation: Unauffällig

\section{Prämorbide Entwicklung}

Unauffällig, das Mädchen wird als ausgeglichen, aufgeschlossen, vergnügt, sensibel, gewissenhaft, fleißig geschildert, es sei eine gute Schülerin, singt und tanzt gern, musiziert und hat Freundinnen.

Erkrankungsbeginn: 14 lahre plötzlich. 


\begin{abstract}
Psychopathologisches Bild
8 Tage dauernde flüchtige psychotische Episode, der Schlaflosigkeit, Appetitlosigkeit, Konzentrationsstörungen und eine Neigung zu Tagträumereien vorausgegangen waren. Das Mädchen hatte wahnhaft-illusionäre Erlebnisse, stand unter dem Einfluss von imperativen akustischen und optischen Halluzinationen, litt unter Veränderungsgefühlen und Derealisationserlebnissen, unter einem quälenden Grübelzwang und Angstzuständen („dass die Russen kommen würden, Atombomben fielen und sie sterben müsse") und äußerte Beziehungsideen. Das Mädchen fühlte sich „von fremden Mächten beeinflusst“ und glaubte, dass seine Handlungen „von außen gesteuert" würden. Nach Abklingen der Episode verhielt sich das Mädchen ruhig, bescheiden, wirkte harmonisch und gut kontaktfähig.

Therapie: Keine

Katamnese (Brief der Mutter) nach 13 Jahren

Die Patientin ist nie wieder erkrankt, hatte gute berufliche Erfolge. Heirat 1958. Lebt seit 1959 in den USA, hat eine 5-jährige Tochter. Die Stimmung sei gut, die Patientin sei sehr beliebt.
\end{abstract}

Eine weitere Untergruppe einer akuten polymorphen Störung ist die „akute schizophreniforme psychotische Störung" (F 23.2). Hier sind die schizophrenen Symptome (Wahnideen, Halluzinationen, Denk- und Sprachstörungen, hebephrene und/oder katatone Symptome) stabil und erfüllen die Kriterien entsprechend F 20, dauern aber weniger als 4 Wochen an.

Correll et al. (2008) haben 26 Jugendliche im Alter von durchschnittlich 15,9 Jahren mit kurz dauernden akuten psychotischen Störungen und nicht näher bezeichneten akuten vorübergehenden psychotischen Störungen prospektiv über einen Zeitraum von durchschnittlich 22 Monaten untersucht und festgestellt, dass 7 von ihnen eine schizophrene oder schizoaffektive und 4 eine bipolare Störung, davon 1 mit psychotischen Symptomen, entwickelt haben. Die Entwicklung in eine schizophrene, schizoaffektive oder eine bipolare Störung mit psychotischen Symptomen war mit dem Vorliegen einer schizotypen Persönlichkeitsstörung vor Erkrankungsbeginn („baseline“) sowie mit einer Beeinträchtigung exekutiver Funktionen assoziiert (untersucht mit dem Wisconsin Card Sorting Test). Dagegen war die Entwicklung zu einer BipolarStörung mit dem gleichzeitigen Vorliegen einer Angststörung verknüpft - was bei den psychotischen Störungen nicht der Fall war. Auch andere Autoren bewerten das Vorliegen einer schizotypen Persönlichkeitsstörung als Risikofaktor für das Entstehen schizophrener Psychosen (McGlashan et al. 2005, Siever u. Davis 2004). Angststörungen sind dagegen mit einem erhöhten Risiko für die spätere Manifestation bipolarer Störungen verknüpft, vor allem bei bipolaren Störungen mit frühem oder sehr frühem Erkrankungsbeginn (Birmaher et al. 2002, Perlis et al. 2004, Wozniak et al. 2002).

\title{
7.6 Psychotische affektive Störungen
}

Im Rahmen affektiver Störungen können zusätzlich zu den depressiven, manischen oder manisch-depressiven Symptomen auch psychotische Symptome (Wahnideen und Halluzinationen) auftreten, z.B. als schwere depressive Episode mit psychotischen Symptomen (F 32.3) oder als Manie mit psychotischen Symptomen (F 30.2). Die Wahnsymptome und Halluzinationen können stimmungskongruent (z.B. Größenwahn bei der Manie oder Schuld-, Versündigungs- oder Verarmungswahn, hypochondri- 
scher Wahn, z.B. an Krebs erkrankt zu sein oder einen langsam verfaulenden Körper zu haben, selbstanklagende Stimmen bei der Depression) oder seltener stimmungsinkongruent sein (z.B. Verfolgungswahn, Vergiftungswahn, Wahn des Gemachten - das eigene Handeln unterliege fremder Kontrolle). Das Auftreten stimmungsinkongruenter Symptome geht häufig mit einer schlechten Prognose einher. Unter 2000 Kindern mit einer affektiven Störung fanden Ulloa et al. (2000) in mehr als 9\% der Kinder assoziierte psychotische Symptome, einschließlich optischen und akustischen Halluzinationen oder Wahnideen. Bei Jugendlichen und Erwachsenen liegt die Häufigkeit bei etwa 15\% (Coryell et al. 1996, Ryan et al. 1987). Verlaufsuntersuchungen von Kindern mit psychotischen affektiven Störungen sind selten.

Die Arbeitsgruppe um Rapoport und Leibenluft (Calderoni et al. 2001) beobachtete häufig, dass Kinder mit einer psychotischen affektiven Störung als „kindliche Schizophrenie“ fehlgedeutet wurden. Ähnliche Beobachtungen wurden von Werry et al. (1991) gemacht: 50\% der Kinder und Jugendlichen mit einer bipolaren Störung wurden ursprünglich als schizophren eingestuft. Die differentialdiagnostischen Schwierigkeiten sind durch mangelnde klinische Erfahrungen aufgrund der Seltenheit psychotischer Störungen des Kindesalters bedingt. Daraus ist zu folgern, dass sorgfältige Nachuntersuchungen und Verlaufsstudien zur Sicherung der Diagnosen bei Kindern erforderlich sind!

Ein Beispiel macht dies deutlich:

Ein Mädchen erkrankt im Alter von 14 Jahren an einer 11 Monate lang andauernden paranoid-halluzinatorischen Episode entsprechend DSM-IV 295.30 bzw. F20.0 (ICD-10). Im späteren Verlauf kommt es zu mehreren, jeweils 2 bis 6 Monate lang anhaltenden depressiven Episoden mit psychotischen Symptomen mit jeweils vergleichbarer Psychopathologie: Schlaf-und Appetitstörungen, diffuse Ängste, Lustlosigkeit, tiefe traurige Verstimmung, Grübelneigung und Müdigkeit. Hinzu kommen stimmungskongruente hypochondrische Wahnideen: Die Patientin befürchtet, an einer Blutvergiftung zu sterben, einen Milzriss oder eine Gehirnblutung zu haben. Sie glaubt, „Eiter im Bauch“ zu haben, der bereits „in ihr Blut übergegangen“ sei. Sie glaubt, sterben zu müssen und hat das Gefühl, dass ihr Körper abstirbt. Immer wieder klagt sie darüber, dass sich ihre Glieder anfühlten, als ob sie abgestorben seien. Da die affektiven Störungen während dieser Episoden überwiegen, und da es sich zu diesem Zeitpunkt um stimmungskongruente Wahnideen und coenästhetische Sensationen handelt, muss die Diagnose lauten: rezidivierende depressive Episoden mit psychotischen Symptomen (DSM-IV 296.34, F33.3).

Bei der ersten psychotischen Episode im Alter von 14 Jahren überwog dagegen die schizophrene Symptomatik: stimmungsinkongruente Beziehungs-, Beeinflussungs- und Vergiftungsideen (die Patientin ißt nichts mehr, weil sie meint, das Essen sei vergiftet), optische und akustische Halluzinationen u.a. in Form von kommentierenden Stimmen. Auch in der ersten Episode schon Angstzustände und hypochondrische Befürchtungen, an einer Blutvergiftung zu sterben (sie sieht in ihrem Gesicht bereits rote Streifen), glaubt, eine Gehirnblutung zu haben, glaubt, sterbenskrank zu sein. Daneben einige Tage lang traurige Verstimmung mit Weinen, Schlaflosigkeit und Rückzug sowie auch tagelang euphorische Stimmung, nach Absetzen von Megaphen wiederum wahnhaft-halluzinatorisch, Beginn einer Elektroschock-Therapie. Nach insgesamt 11 Monaten Vollremission. Während der ersten Episode überwiegt also ein- 
deutig die schizophrene Symptomatik, und die affektiven Symptome treten demgegenüber weitgehend in den Hintergrund. Danach ändert sich die Psychopathologie, die Psychose geht über in rezidivierende depressive Episoden mit psychotischen Symptomen.

Vor allem die Unterscheidung zwischen stimmungskongruenten und -inkongruenten psychotischen Symptomen (Wahnideen und Halluzinationen) ist wichtig für die diagnostische Einschätzung. Diese hat prognostische und therapeutische Konsequenzen: Die Prognose affektiver Störungen mit psychotischen Symptomen ist günstiger als die der kindlichen Schizophrenie, und sie sollten in erster Linie mit Antidepressiva bzw. Stimmungsstabilisierern behandelt werden. Im Übrigen unterscheiden sich beide Krankheitsbilder auch hinsichtlich der familiären Belastung - überwiegend depressive und bipolare Erkrankungen in der Aszendenz von Kindern mit affektiven Störungen und vice versa.

\subsection{Schizoaffektive Psychosen}

Die schizoaffektiven Psychosen nehmen nosologisch eine Mittelstellung zwischen schizophrenen Psychosen einerseits und affektiven Störungen andererseits ein. Die Diskussion um die Berechtigung einer gesonderten diagnostischen Kategorie für diese Psychosengruppe hält bis in die Gegenwart an (Craddock et al. 2009, Lake u . Hurwitz 2007, Laursen et al. 2009, Marneros 2006). In einem späteren Kapitel werden wir uns mit dieser Thematik unter dem Stichwort „Einheitspsychose“(s. Kap. 8.4.8.6) auseinandersetzen. Vor allem aus praktischen, nämlich prognostischen und therapeutischen Gründen ist es sinnvoll, am Krankheitskonzept der schizoaffektiven Psychosen festzuhalten, und wir stimmen mit Marneros darin überein, dass psychiatrische Diagnosen praxisorientiert und sowohl für den Arzt, Patient und Forscher nützlich sein und nicht „als ein algorithmisches Konstrukt“ betrachten werden sollten, welche „feste, unerschütterliche nachgewiesene biologisch-genetische Zustände“ beschreibt (Marneros 2008, S. 359).

Es wird kritisch diskutiert, ob die schizoaffektiven Psychosen eine eigenständige nosologische Entität oder lediglich Varianten schizophrener oder affektiver Erkrankungen darstellen.

Von den beiden gegenwärtigen etablierten internationalen Klassifikationssystemen psychiatrischer Erkrankungen in ihrer jeweils revidierten Fassung ist die ICD-1o relativ weitherzig, dafür eher praxisorientiert im Vergleich zum recht eng gefassten DSM-IV, das verfeinerter, raffinierter, deutlich anspruchsvoller ist und großen Wert auf Operationalisierbarkeit der Kriterien legt.

Beide Klassifikationssysteme legen zu recht Wert darauf, dass die Diagnose einer schizoaffektiven Störung nur dann gestellt werden darf, wenn neben eindeutig schizophrenen Symptomen wie Wahn und Halluzinationen, die mindestens 2 Wochen anhalten müssen, affektive Störungen vorkommen, die ebenfalls zeitlich einen erheblichen Anteil an der Symptomatik ausmachen müssen. Das heißt, kurzfristige depressive oder maniforme Erscheinungen im Rahmen einer rezidivierenden oder chronisch verlaufenden Schizophrenie und vice versa, im Vergleich zum Gesamtverlauf kurzfristig oder nur wenig ausgeprägt wahnhafte oder halluzinatorische oder 
andere schizophrene Symptome im Verlauf einer affektiven Störung, rechtfertigen nicht die Diagnose einer schizoaffektiven Erkrankung.

In der ICD-1o hat die Diagnose einer schizoaffektiven Psychose zur Voraussetzung, dass sowohl affektive als auch schizophrene Symptome in derselben Krankheitsepisode unzweideutig mindestens zwei Wochen lang vorhanden sind. Je nach der vorherrschenden affektiven Symptomatik werden die einzelnen Episoden als „schizoaffektive Störung gegenwärtig manisch“, „gegenwärtig depressiv“ oder ,gegenwärtig gemischt“ klassifiziert, wobei im letzeren Fall schizophrene Symptome und Symptome einer gemischten bipolaren Störung nebeneinander vorkommen. Wichtig ist, dass die psychotischen Symptome (Wahn, Halluzinationen) stimmungsinkongruent sind. Zur Veranschaulichung sei das Krankheitsbild einer Patientin unserer Essener Klinik wiedergegeben.

\section{Fallbeispiel}

Die Mutter und Großmutter mütterlicherseits litten beide an rezidivierenden depressiven Verstimmungszuständen und sind beide deshalb wiederholt stationär behandelt worden. Die Mutter des Mädchens hat 2-mal einen Suizidversuch unternommen. Ein $1 / 2$ Jahr vor Beginn der Erkrankung machte das zu diesem Zeitpunkt 15 1 J Jahre alte Mädchen eine reaktive Depression durch, nachdem es erfahren hatte, dass die Großmutter mütterlicherseits an Krebs erkrankt war. Das Mädchen hatte panische Angst, dass die Großmutter sterben könnte und reagierte auf einen Streit zwischen der Mutter und der Großmutter mit einer starken depressiven Verstimmung. Das Mädchen habe furchtbar geweint und sei lange Zeit sehr traurig gewesen. Im Alter von 16 Jahren erkrankte das Mädchen dann akut an einer schizomanischen Phase mit Größenideen, starker Hypermotorik, Schlaflosigkeit, Konzentrationsstörung, Logorrhoe, Ideenflüchtigkeit und umtriebigem Verhalten. Das Mädchen schlief schließlich überhaupt nicht mehr, war äußerst umtriebig, dauernd in Aktivität, habe nachts laute Musik gehört, zeitweilig habe es nur noch französisch gesprochen, dann nur noch sinnlos aneinandergereihte Fremdwörter. Es habe geäußert, sich mit Paul McCartney von den Beatles zu treffen, der in sie verliebt sei, er hole sie von der Schule ab und fliege mit dem Hubschrauber mit ihr zusammen fort. Die Stimmung war euphorisch gehoben, manisch, der Gedankengang inkohärent, es bestanden eine ausgeprägte Logorrhoe, Wahneinfälle, Wahnvorstellungen, Personenverkennungen und stimmungsinkongruente optische Halluzinationen. So hatte die Patientin u.a. einen gelben Ring gesehen.

Alles, was schwarz war, hatte sie als teuflisch bzw. als vom Teufel kommend erlebt. Sie hatte gemeint, dass Frauen tagsüber blondes und nachts schwarzes Haar hätten.

Außerdem litt das Mädchen an paranoiden Ideen, es glaubte, dass die Mitpatienten in der Klinik Masken aufhätten und es vergiften wollten, deshalb hatte es zeitweise nichts gegessen; auch hatte sich das Mädchen vorgestellt, dass es "die Eva aus dem Paradies" sei und dass sein Leben „wieder bei Null beginnen“ könne. Später, nach etwa $1 / 2$ lahr, meinte die Patientin, dass sie vielleicht deswegen krank geworden sei, weil sie so schreckliche Erlebnisse mit ihrer Mutter und Großmutter gehabt habe. Das Mädchen zog sich nackt aus, tanzte in der Wohnung und außerhalb der Wohnung herum und musste schließlich 6 Wochen lang geschlossen stationär behandelt werden. Die schizomanische Phase ging in ein depressives Zustandsbild mit Apathie, trauriger Verstimmung, Grübelneigung, Selbstvorwürfen, Rückzug und Aspontaneität über, was etwa ein Vierteljahr anhielt. Danach wieder euphorische Stimmung, Konzentrationsstörungen, Müdigkeit, kleinkindhaftes Verhalten mit sozialen An- 


\begin{abstract}
passungsstörungen und auffallende Apathie, deutlich reduzierte affektive Reagibilität, das Mädchen schien emotionsarm, war passiv, desinteressiert, äußerte, sich weder freuen noch traurig sein zu können, es wirkte unlebendig und starr. Ein Dreivierteljahr nach Beginn der Erkrankung wirkte das Mädchen affektflach, antriebsarm, retardiert, es schien insgesamt auf der Entwicklungsstufe eines 10-jährigen Mädchens zu stehen und verhielt sich nicht altersadäquat. Es bestanden leichte, aber deutliche Zeichen einer postpsychotischen Defizienz mit Antriebsarmut, affektiver Verflachung und mangelnder emotionaler Reagibilität.
\end{abstract}

Das beschriebene 16-jährige Mädchen war mütterlicherseits (Großmutter, Mutter) mit schweren Depressionen belastet. Es litt selber an einer lang dauernden schizomanischen Episode mit eindeutigen manischen und psychotisch-schizophrenen Symptomen, die gleichzeitig (konkurrent) nebeneinander bestanden. Nach Abklingen der schizomanischen Episode folgte unmittelbar eine rein depressive Episode (3 Monate), auf die wiederum eine manische Phase ohne psychotische Symptome folgte. Das Krankheitsbild entsprach somit entsprechend ICD-10 einer schizoaffektiven Psychose (F 25.20).

Nach DSM-IV ist Voraussetzung für die Diagnose einer schizoaffektiven Störung das Vorhandensein einer ununterbrochenen Krankheitsepisode, während der für einige Zeit eine Episode einer major depression, eine manische Episode oder eine gemischte Episode gleichzeitig mit schizophrenen Symptomen (Wahn, Halluzinationen, katatone oder desorganisierte Verhaltensweisen) vorkommen. Zusätzlich wird gefordert, dass während ein und derselben Krankheitsperiode mindestens zwei Wochen lang Wahn oder Halluzinationen vorkommen, ohne „dass ausgeprägte affektive Symptome bestanden haben“, d.h. wenn affektive Symptome vorhanden sind, sollen sie in dieser Zeit nicht im Vordergrund stehen. Im Übrigen müssen die affektiven Symptome „während eines erheblichen Teils der gesamten Krankheitsdauer“ vorhanden sein. Hinzu kommt, dass die affektive und schizophrene Symptomatologie im Verlauf einer „einzigen, ununterbrochenen Krankheitsperiode“ auftritt. Mit dem Begriff „Krankheitsperiode“ ist der Zeitabschnitt gemeint, während dessen der Patient fortlaufend floride oder residuale Symptome seiner psychotischen Erkrankung zeigt. Wie bei schizophrenen Psychosen ist die Mindestdauer der schizoaffektiven Störung ein Monat, die Episode einer major depression muss mindestens zwei Wochen, eine manisch oder gemischte Episode mindestens eine Woche andauern, Wahnphänomene oder Halluzinationen müssen ebenfalls mindestens zwei Wochen andauern, und zwar bei gleichzeitiger Abwesenheit ausgeprägter affektiver Symptome.
Weiterhin ist zu beachten, dass die depressive Symptomatologie bei den schi- zoaffektiven Störungen in Analogie zur Diagnose einer major depression nicht nur Symptome von Freudlosigkeit oder Interessensverlust oder Initiativearmut umfassen dürfen, sondern dass stets eine „tiefgreifende depressive Stim- mungslage" vorliegen muss!

Nach DSM-IV wird gefordert, dass die affektiven Symptome „für einen erheblichen Anteil an der Gesamtdauer der Störung “ andauern, das bedeutet, dass, wenn affektive Symptome relativ kurz im Vergleich zur Gesamtdauer der Psychose vorhanden sind, die Diagnose einer Schizophrenie zu stellen ist. Außerdem legt das DSM-IV Wert 
darauf, dass Wahn oder Halluzinationen für mindestens 2 Wochen bei gleichzeitigem Fehlen ausgeprägter affektiver Symptome bestehen. Treten psychotische Symptome nur im Verlauf einer Periode einer affektiven Psychose auf, dann muss die Diagnose heißen: „affektive Störung mit psychotischen Merkmalen“. Auch muss geprüft werden, ob die depressiven Symptome wie Schlafstörungen, Appetit- und Essstörungen, Gewichtsabnahme nicht Folge von schizophrenen Symptomen sind, also z.B. von imperativen akustischen Halluzinationen oder von Vergiftungsideen.

Ein Beispiel für die Unterschiedlichkeit der diagnostischen Kriterien von ICD-1o und DSM-IV ist die im Alter von 13 Jahren beginnenden Psychose eines intellektuell und musikalisch sehr begabten Jungen, der väterlicherseits mit depressiven Erkrankungen belastet ist. Die Psychose begann im Alter von 13 Jahren mit einer manisch-depressiv-schizophrenen Mischsymptomatik. Morgens war er depressiv, abends manisch. Konkurrent traten schizophrene Symptome auf in Form von dialogischen Stimmen und stimmungsinkongruenten Beziehungs- und Beeinflussungsideen. Dauer: 2 Monate.

Unter Zugrundelegung der ICD-1o wäre die Diagnose: „gemischte schizoaffektive Störung“ (F25.2): Kennzeichnend sind Störungen, bei denen Symptome einer Schizophrenie (F20.0) mit solchen einer gemischten bipolaren Störung (F31.6) gemeinsam vorhanden sind und gleichzeitig bestehen.

Nach DSM-IV muss die schizophrene Symptomatologie jedoch getrennt, d.h. ohne gleichzeitige affektive Störung zwei Wochen lang anhalten, was hier nicht der Fall war, sondern es handelte sich um ein gleichzeitiges Vorkommen von depressiven, manischen und stilrein schizophrenen Symptomen während ein und derselben Krankheitsepisode. D.h. nach DSM-IV muss die Diagnose lauten: „gemischte Episode mit psychotischen Symptomen" (296.64).

Eine Hauptschwierigkeit der beiden Klassifikationssysteme liegt darin, dass jeweils einzelne Episoden klassifiziert werden, nicht jedoch der Gesamtverlauf. Dies bereitet bei der Vergabe von Gesamtdiagnosen im Langzeitverlauf erhebliche Probleme, und Marneros (1995) stellt zu recht die Frage: „Haben diese Patienten mehrere unterschiedliche Erkrankungen? Soll immer wieder eine neue Diagnose gestellt werden?“. Und er spricht sich gegen unterschiedliche diagnostische Etikettierungen der verschiedenen Episoden im Gesamtverlauf aus („Psychische Erkrankungen sind keine Eintagsfliegen“). Stattdessen stellt er eine „empirisch-klinische“ Definition der schizoaffektiven Störungen vor, die sich auf Langzeitverläufe stützt. So definiert er schizoaffektive Erkrankungen als Störungen, „die gleichzeitig eine schizophrene und eine affektive Symptomatik aufweisen " oder bei denen die beiden Symptomkonstellationen abwechselnd vorkommen, unabhängig von der Dauer des dazwischen liegenden Intervalls. Es werden also konkurrente und sequentielle Verlaufsformen unterschieden. Es ist leicht einsehbar, dass diese praxisorientierte Definition pragmatischer und einfacher handhabbar ist.

Die diagnostische Einschätzung einer schizoaffektiven Störung bereitet also ganz besondere Schwierigkeiten. Umso mehr Sorgfalt muss angewendet werden.

Gerade im Jugendalter bestehen große Unsicherheiten bei der Differenzierung affektiver, schizoaffektiver und schizophrener Störungen. Darauf wird auch immer wieder hingewiesen. So hat Joyce (1984) 200 konsekutive Aufnahmen einer Klinik in Neuseeland mit der DSM-III Diagnose „Affektive Psychose“ nachuntersucht und dabei aus den Krankenakten die früheren Diagnosen bei deren Erstmanifestation erfasst. Dabei 
ergab sich, dass bei 66 von den 200 Patienten (33\%) die Diagnose Schizophrenie gegeben worden war. Diese „Fehlklassifizierungen“ waren stark altersabhängig: Bei einer Erstmanifestation unter 20 Jahren waren es 36 von 6o (60\%), im Alter von 20-29 Jahren 23 von $73(32 \%)$ und bei den über 30 Jahre erstmals erkrankten Patienten waren es nur noch 7 von $67(10 \%)$, bei denen ursprünglich eine Schizophrenie diagnostiziert worden war.

Interessant ist, dass bei den unter 20-jährigen die Diagnose Schizophrenie in 38\% der depressiven und in $72 \%$ (!) der manischen Störungen gegeben wurde, was der bekannten Tatsache entspricht, dass Manien in einem früheren Lebensalter häufig als Schizophrenie fehlinterpretiert werden.

Carlson et al. (1994) diskutieren mögliche Gründe für diese Abweichungen in der Klassifizierung. Sie vermuten, dass die manischen Störungen im Jugendalter komplizierter sind als bei Erwachsenen und häufig kombiniert sind mit Alkohol- und Drogenkonsum, Verhaltensstörungen u.a. Die Autoren haben überprüft, ob der „Bias“ zur Schizophrenie bei jugendlichen affektiven Störungen nach Einführung der ICD-1o und des DSM-IV noch fortbesteht und gefunden, dass die Diagnose „Manische Störung “ bei Jugendlichen immer noch unterrepräsentiert ist, jetzt allerdings, vermutlich wegen der enger gefassten Diagnose, nicht mehr als „Schizophrenie“ sondern z.B. als „schizophrenieform“ oder als „reaktive Schizophrenie“ eingestuft wird.

Die zahlenmäßig umfangreichste Untersuchung zum Thema „Fehldiagnosen“ im Jugendalter hat Thomsen (1996) vorgelegt. Er hat alle Patienten unter 18 Jahren erfasst, die in Dänemark in den Jahren 1970-1993 mit der ICD-8 Diagnose „Schizophrenie“ stationär aufgenommen worden sind. Von diesen 312 Patienten konnte er bei 209 den Verlauf über 10 Jahre verfolgen. In $n=134$ Fällen $(64 \%)$ wurde die Diagnose bestätigt. Bei den übrigen 75 (36\%) wurden nach dieser Zeit andere Klassifizierungen vorgenommen, davon in über 50\% Persönlichkeitsstörungen (meist „Borderline“). Bei 10 der 209 jugendlichen Patienten wurde nach 10-jährigem Verlauf die Diagnose einer manisch-depressiven Störung gestellt.

Im Langzeitverlauf können auch stilrein schizophrene Episoden mit schizoaffektiven oder affektiven Episoden getrennt voneinander abwechseln. Das entspräche dem sequentiellen Typ einer schizoaffektiven Psychose. Unsere Untersuchungen haben ergeben, dass es im Langzeitverlauf zu einem Syndromwechsel („syndrome shift“) vom Schizophrenen zum Affektivem und umgekehrt kommen kann, und dass sich stilrein schizophrene mit depressiven Episoden abwechseln können (Eggers 1989, Eggers et al. 2002, Röpcke und Eggers 1999) (Näheres hierzu im Kap. 8).

\section{Fallbeispiel}

Bei einem hochgradig mit affektiven Störungen und Suiziden in der Aszendenz belasteten Mädchen trat im Alter von 6 Jahren ein kurzdauernder depressiver Zustand mit Weinen, Antriebslosigkeit, schwerer Schlafstörung und Grübelneigung auf. Im Alter von 12 Jahren erneute mehrere Wochen anhaltende depressive Phase, mit 13 Jahren kam es zu einer mehrwöchigen schizomanischen Phase, auf die wiederholt kurzdauernde depressive Verstimmungszustände folgten. Ab dem Alter von 16 Jahren entwickelte sich eine hebephrene Symptomatik, die mit 18/19 Jahren zunehmend eine paranoide Färbung mit katatonen Erregungszuständen, Denkzerfahrenheit und akustischen Halluzinationen annahm. Seit dem 
20. Lebensjahr kommt es immer wieder zu rezidivierenden kataton-stuporös-halluzinatorischen Episoden mit zunehmender Persönlichkeitsveränderung. Zwischen den psychotischen Episoden besteht eine konstante paranoid-hebephrene Symptomatik.

In diesem Krankheitsverlauf kommen anfänglich schizomanische und rein depressive Episoden vor, die im Alter von 16 Jahren in eine rezidivierende rein schizophrene Psychose ohne weitere affektive Elemente einmündet.

Es gibt auch die umgekehrte Verlaufsrichtung: Beginn mit schizoaffektiven Episoden und Übergang in eine rezidivierende bipolare Störung.

\section{Fallbeispiel}

Im Alter von 13 lahren erkrankte ein Junge an einer 2 Monate anhaltenden schizoaffektiven Störung, gegenwärtig bipolar, entsprechend F 25.2 bzw. 295.70. Außer einer Großmutter väterlicherseits, die an rezidivierenden Depressionen litt, war die Familienanamnese unauffällig. Die prämorbide Entwicklung des Jungen verlief völlig regelrecht, der Junge galt als etwas verschlossen und zu Jähzorn neigend, war gut kontaktfähig, hatte Freunde, spielte Geige und trieb Sport. Gute Intelligenz (HAWIE: Gesamt-IQ 113 (121/103)).

Die schizoaffektive Episode war gekennzeichnet durch ein Nebeneinander von depressiven, manischen und paranoid-halluzinatorischen Symptomen. Der Junge war "verstört", litt unter Antriebs- und Sprachlosigkeit, machte sich Vorwürfe, er sei schlecht und komme deshalb auf den elektrischen Stuhl, er sei der Teufel, er sei Adolf Hitler, habe die Prostituierte Nitribitt ermordet und Schloss Linderhof bestohlen. Abends war er manisch, aufgedreht, logorrhoisch, trieb allerlei Schabernack und äußerte Größenideen, z.B. sei er der Fußballspieler Pelé. Gleichzeitig litt er unter Beziehungsideen und hörte imperative und kommentierende Stimmen. Er glaubte, dass schlecht über ihn geredet würde und dass in den Deckenlampen Fernsehapparate eingebaut seien, die ihn beobachteten. Therapie: ES (Elektroschocks), IS (Insulinschocks), Neuroleptika.

Das Krankheitsbild ging 2 Monate später in eine zyklothyme Störung (F 34.0, 301.13) über, welche 1 Jahr und 10 Monate andauerte. Im Alter von 15,3 Jahren erkrankte der Patient wiederum an einer 4 Monate andauernden schizoaffektiven Störung vom gemischt-bipolaren Typ. Es bestand eine Mischsymptomatik mit hebephrenen, katatonen, paranoiden und halluzinatorischen sowie wechselnd depressiven und manischen Symptomen. Der Junge fühlte sich verfolgt und hörte die Stimmen von Geistern und Kobolden. Sein Denken war zerfahren („Man kann denken, spricht es aber nicht aus ... Krankheit kann man nicht selbst machen, Gesundheit kann man sich selbst nicht geben. Machen und Geben und Dürfen, dasselbe ... Wenn man es vom ersten Ursprung betrachtet, dann ist es die Menschheit, das Geschöpfte und Tieres... Man bezeichnet es Neutron ...). Sein Ausdrucksgebaren war maniriert, bizarr, der Patient grimassierte, war läppisch, albern, zynisch, umtriebig, gereizt und affektiert. Immer wieder erhebliche Unruhezustände mit unmotiviertem Schreien, Kotschmieren und -werfen, Bespucken der Wände unter Mitpatienten. Therapie: ES, IS, Neuroleptika. Teilremission.

Ab dem Alter von 16 lahren traten bis zum Zeitpunkt der zweiten Nachuntersuchung im Alter von 45,6 lahren zunächst eine gemischte Bipolar--Störung (F 31.6, 296.63) und anschließend 15 manische Episoden ohne psychotische Symptome auf entsprechend F 31.1, 296.43, die bis zu 6 Monaten anhielten, schwer bis mittelschwer ausgeprägt waren und jeweils voll remittierten. 


\begin{abstract}
Nachuntersuchung
Der Patient zeigt ein freundliches, sympathisches, offenes Wesen mit jungenhaftem Charme. Er ist gemütsmäßig schwingungsfähig, stets freundlich, zugewandt, stellt sich gut auf die Gesprächsthemen ein und strahlt viel Sympathie aus. Seine Stimmung wirkt leicht gehoben, der Antrieb etwas gesteigert, oberhalb der Norm. Pausenlos ist er in Aktion, holt Sachen hervor, ist beschäftigt, das macht inn gelegentlich etwas anstrengend, was auch seine Frau bestätigt. Dabei ist er empathisch und freundlich, bedankt sich und richtet Grüße aus. Etwa alle 2 Jahre traten bei ihm maniforme Phasen mit motorischer Unruhe, rastloser Getriebenheit, Schlaflosigkeit, Rededrang, inkohärentem Gedankengang, starker Gereiztheit und Aggressivität auf. Sie dauerten jeweils $1 \frac{1}{2}$ bis $2 \frac{1}{2}$ Monate und traten regelmäßig in den Herbstmonaten auf. Seit 4 lahren ist der Patient verheiratet, er hat viele Musikerfreunde, spielt in zwei Orchestern der Stadt Frankfurt, beherrscht 4 Instrumente (Tenor-Saxophon, Klarinette, Geige und Bratsche) und komponiert Streichquartette und Streichtrios. Ansonsten arbeitet er in der Finanzbuchhaltung der Caritas.
\end{abstract}

Die folgende Fallgeschichte ist ein eindrucksvolles Beispiel für die Verlaufsentwicklung vom Schizophrenen zum Affektiven: Nach einer fast ein Jahr andauernden schizophrenen Episode (F 20.0, 295.30) im Alter von 14 Jahren kommt es bei dem prämorbid völlig unauffälligen Mädchen zu rezidivierenden Episoden einer Major Depression mit psychotischen Episoden (F 33.3, 296.34), welche bis zu 5 Monate lang anhalten und intervallär mit Teil- oder Vollremissionen einhergehen. Ab dem Alter von 25 Jahren traten saisonale leichte bis mittelgradige depressive Phasen jeweils im Frühjahr und Herbst auf (F 33.0, F 33.1, 293.31), welche ab dem Alter von 14 Jahren in hochgradig hypochondrisch-ängstliche Verstimmungszustände mit Körpermissempfindungen, Panikattacken und Todesangst übergehen (F 41.o), die jeweils 4-8 Wochen andauern. Interessant ist, dass somit die Thematik der ersten psychotischen Episode im Alter von 14 Jahren wieder erscheint - s. Fallbeispiel! Bei der zweiten Nachuntersuchung im Alter von 55 Jahren, knapp 41 Jahre nach Erkrankungsbeginn, bestanden keinerlei Anhaltspunkte für eine postpsychotische Wesensänderung, weder hypochondrische Ideen, noch Ängste, somit Vollremission. Heirat im Alter von 24 Jahren, 5 Jahre später Geburt ihres Sohnes.

\title{
Fallbeispiel
}

\section{Familienanamnese}

Der Großvater väterlicherseits der Patientin litt an rezidivierenden Depressionen, eine Schwester des Vaters unternahm wiederholt Selbstmordversuche, eine andere "nervenkrank“, Alkoholikerin. Eine Schwester der Patientin erkrankte im Alter von 24 Jahren an einer schizoaffektiven Psychose.

Die prämorbide Entwicklung ist unauffällig. Das Mädchen hat 12 jüngere Geschwister. Es wird als gute Schülerin, weich, gutmütig, sehr gut kontaktfähig beschrieben.

Erkrankungsbeginn: Plötzlich mit Unruhe, Angst, hypochondrischen Ideen, Beziehungs- und Vergiftungsideen, optischen und (imperativen) akustischen Halluzinationen. Das Mädchen steht nachts plötzlich auf, steht auf dem Flur, ist ratlos, beschaut sich von oben bis unten und fragt, „Ob ich auch keine Blutvergiftung kriege“. Es hat Angst, alle möglichen Krankheiten zu bekommen, bezieht alles auf sich, wenn es irgendetwas über Krankheiten hört, 
ißt nicht mehr und glaubt, das Essen sei vergiftet. Das Mädchen äußert immer wieder, nicht mehr lange zu leben und fragt immer wieder, „Es wird doch nicht so schlimm sein?“. Es steht dauernd vor dem Spiegel, will nachts nicht alleine schlafen. Es äußert, es werde „ihre Gedanken nicht los". Das Mädchen berichtet über optische Halluzinationen: „Da sehe ich den Friedhof und jetzt sehe ich noch den Sarg". Nachts sehe sie dunkle Männer auf dem Friedhof, alles sei „wie in die Ferne gerückt“.

Die Patientin glaubte, dass ihre Gedanken beeinflusst würden, "der Böse“ sei bei ihr und beeinflusse sie. Wenn sie etwas vom "Heiland“ lese, dann sage jemand "lies das nicht“. Es seien „Gedanken, die das so sagen“. Sie ist überzeugt, „eine Gehirnblutung" zu haben. Sie hört Stimmen, die ihr Handeln kommentieren und ihr Befehle geben. Außerdem „höre sie ihre eigenen Gedanken“ (Gedankenlautwerden). Sie klagt darüber, keine Luft zu bekommen und leidet täglich unter Angstzuständen, glaubt fest daran, krank zu sein, eine schwere Gehirnblutung, eine Blutvergiftung, eine Darmverschlingung etc. zu haben. Sie glaubt, ihre Milz sei zerrissen.

\section{Weiterverlauf (Nachbeobachtungszeit 41 Jahre)}

Rezidivierende depressive Episoden mit psychotischen Symptomen und später, ab dem Alter von 25 lahren, depressive Phasen ohne psychotische Symptome. Die hypochondrischen Themen mit entsprechenden Ängsten, an unterschiedlichen Krankheiten zu leiden und sterben zu müssen, bleiben konstant. Immer wieder hat sie die Vorstellung, an einer „Eiteransammlung" im Unterbauch zu leiden und dass der Eiter bereits ins Blut übergegangen sei und dass sie eine Blutung im Gehirn habe. Die Krankheits- und Todesvorstellungen nehmen teilweise zwanghaften Charakter an in Form von Zwangsgedanken und -befürchtungen. "Diese Gedanken gehen und gehen oft nicht aus dem Kopf heraus". Bei der ersten Nachuntersuchung im Alter von 27 lahren äußert die Patientin leibhypochondrische Beschwerden. Vor allem morgens beim Aufwachen verspüre sie "schon mal so einen Schlag in meinem Kopf, ganz eigenartig, ganz fremdartig“, sie könne das gar nicht recht beschreiben, es sei, „als wenn etwas zerplatzt“, „wie eine Blase in meinem Kopf“. Ansonsten bestehen Ängste vor Verkehrsunfällen. Psychotische Symptome, wie sie während der ersten Episode vorkamen, sind nicht mehr aufgetreten. Die depressive Symptomatik im Herbst und im Frühjahr sei seit etwa 15 lahren fast ganz verschwunden, sie leide aber noch immer unter etwas trüberen Gedanken und Stimmungen in dieser Jahreszeit. Es sei aber gar kein Vergleich mehr mit den früheren Zuständen. Außer Flugangst habe sie auch keine Ängste mehr.

Bei der zweiten Nachuntersuchung im Alter von 55 Jahren schildert sie sich als gewissenhaft, ordentlich, auch skrupulös. Sie mache sich viele Gedanken und sorge sich. Sie vermeide das Alleinsein und im Kollegenkreis sei sie sehr beliebt. Sie erscheint ausgesprochen sympathisch und warmherzig.

Fazit: Bei dem im Alter von 14 Jahren erkrankten, prämorbid unauffälligen und familiär mit affektiven und schizoaffektiven Psychosen belasteten Mädchen bestand nur zu Erkrankungsbeginn eine schizophrene paranoid-halluzinatorische Symptomatik von 11 Monaten Dauer. Danach war die Symptomatik ausschließlich affektiver Natur: Häufig rezidivierende Episoden einer Major Depression mit psychotischen Symptomen und mittelschweren Bipolar-I-Störungen (gemischt, manisch oder depressiv) gingen schließlich in leichtere bis mittelgradige saisonale Frühlings- und Herbstdepressionen über, die jeweils bis zu 12 Wochen anhielten. Erstaunlich ist die Kontinuität der depressiv-ängstlich gefärbten leibhypochondrischen Befürchtungen und Emp- 
findungen, wobei sich die Symptomatik in den letzten Jahren fast vollständig zurückgebildet hat (Vollremission).

Die rein schizophrene Symptomatik kann sich bei sequentiellen Verlaufsformen schizoaffektiver Psychosen des Kindes- und Jugendalters aber auch erstmalig spät manifestieren und dann bildbeherrschend sein und zu einem ungünstigen Krankheitsausgang führen. So traten bei einer im Alter von 14 Jahren akut an einer 5 Monate andauernden schizoaffektiven Psychose (F 25.2, 295.70) erkrankten Mädchen erstmals im Alter von 49 Jahren jeweils ein Monat andauernde paranoid-halluzinatorische Episoden auf (F 20.0, 295.30), während zwischen dem Alter von 16 bis 52 Jahren sehr häufig rezidivierende schizoaffektive Episoden (vorwiegend gemischt-bipolar, F 25.2, 295.70) und Bipolar-I-gemischte oder depressive Phasen mit und ohne psychotische Symptome (F 31.6, 296.6, F 31.5, 296.54, F 31.4, 296.53) das Symptombild beherrschten und jeweils bis zu 6 Monate anhielten. In den schizoaffektiven Episoden hörte die Patientin u.a. Stimmen, mit denen sie sich unterhielt, und die ihre Gedanken und Handlungen kommentierten. Ab dem Alter von 52,4 Jahren traten nur paranoid-halluzinatorische und keine schizoaffektiven oder affektiven Episoden mehr auf. Zum Zeitpunkt der zweiten Nachuntersuchung im Alter von 55,2 Jahren bestanden eine kontinuierliche paranoid-halluzinatorische Symptomatik (F 20.0, 295.30), welche $2 \frac{1}{2}$ Jahre andauerte, und gleichzeitig ausgeprägte postschizophrene Persönlichkeitsveränderungen sowohl in affektiven als auch intentionalen Bereich (F 20.5, 295.60). Schlechte Sozialremission (DAS-M: 4).

Die Patientin leidet an einer chronischen akustischen Halluzinose mit kommentierenden Stimmen, mit denen sie sich unterhält, sowie an paranoiden Verfolgungs-, Beziehungs-, Beeinträchtigungs- und Größenideen; dazu: formale Denkstörungen, Denkzerfahrenheit und Gedankendrängen. Die Stimmen würden schlecht über sie reden, z.B. sie sei eine Hure, eine „Tussi“, ein „schlechtes Mädchen“. Sie sei von „Selbstbefriedigern“ umstellt, die sie verfolgten mit „Anspielungen“ und Telefonanrufen. Immer wieder glaubt sie, umgebracht zu werden und ruft dann die Polizei an. Vor allem Frauen sind es, die sie durch ihren Neid und ihre Eifersucht verfolgen, aber auch die Liebesobjekte selbst, die Objekte ihres „Liebeswahns“, reden schlechten über sie und bestechen andere mit sehr viel Geld, damit diese schlecht über sie reden. Dies alles macht sie sehr zornig und wütend, sie schreit mit lauter und greller Stimme ihren Zorn aus sich heraus. Andererseits ist sie depressiv verstimmt, vorwiegend morgens. Zeitweise ist die Patientin aber auch manisch-enthemmt, übertrieben heiter, energiegeladen, und sie glaubt, dass sie es ist, die den Weltfrieden gerettet und den Dritten Weltkrieg verhütet habe (maniforme Größenideen). Es kommt zu jähen Stimmungsumschwüngen zwischen depressiver Verstimmtheit mit Apathie einerseits und manischer Gehobenheit andererseits. Während des Gesprächs mit ihr sind solche Stimmungsumschwünge immer wieder zu beobachten, von weinerlich-klagsamer Verzweiflung bis zu läppisch anmutender Heiterkeit. Trotz einer deutlichen affektiven Verflachung verfügt sie über Humor und auch Zeichen von echt anmutender Teilnahmefähigkeit!

Bemerkenswert ist auch bei dieser Patientin die Kontinuität der psychotischen Inhalte im Langzeitverlauf: Bereits bei Erkrankungsbeginn im Alter von 13 Jahren hatte die Patientin die gleichen paranoiden Ideen wie heute: Alle Leute auf der Straße schauten sie so komisch an und lachten sie aus. Sie glaubte, dass man vielleicht über sie rede. Auch damals grundloses Weinen und rascher Stimmungsumschwung von Weinen zu läppisch gehobener Stimmung mit inadäquatem Lachen. Auch damals akustische 
Halluzinationen, die zunächst vorwiegend mit der Mutter zu tun hatten. Auch damals schon die Wahnvorstellung, dass sie umgebracht werden solle.

Bei einer anderen Patientin trat die erste paranoid-halluzinatorische Episode (F 20.0, 295.3) im Alter von 24 Jahren auf und hielt 5 Monate lang an. Zuvor war die Patientin bereits im Alter von 9 Jahren (!) an einer 3 Monate andauernden depressiven Phase mit multiplen somatischen Symptomen (Globusgefühl, Beklemmungsgefühle, Herzsensationen, Erstickungsfurcht) und ausgeprägter Zwangssymptomatik erkrankt (F 32.11, 296.22). Nach einem symptomfreien Intervall von $1 \frac{1}{2}$ Jahren Dauer kam es im Alter von 10,7 Jahren zu einem Rezidiv, einer 3 Monate anhaltenden depressiven Episode mit psychotischen Symptomen (F 33.3, 296.34). Bis zum Alter von 24 Jahren erkrankte die Patientin an vier weiteren jeweils 3-5 Monate andauernden depressiven Episoden mit somatischen u./o. psychotischen Symptomen, bevor die Psychose in abwechselnd schizophrene (paranoid-halluzinatorische) und schizoaffektive Episoden überging mit Ausbildung eines schizophrenen Residuums (ab dem Alter von 28 Jahren).

Der gesamte Krankheitsverlauf über einen Zeitraum von 47 Jahren ist in Tabelle 16 dargestellt.

\section{Tab. 16 Krankheitsverlauf einer schizoaffektiven Psychose - Verlaufsrichtung vom Affektiven zum Schizophrenen - Erkrankungsbeginn 9 Jahre}

\begin{tabular}{|c|c|c|c|}
\hline Zeitraum & Alter & Diagnose & Behandlung \\
\hline 1. Episode 1947 & $\begin{array}{l}9 \text { lahre } \\
\text { (3 Monate) }\end{array}$ & $\begin{array}{l}\text { Mittelgradige depressive Episode mit } \\
\text { somatischen Symptomen } \\
\text { (F32.11/296.22) }\end{array}$ & - \\
\hline Intervall 1947 bis 1949 & $\begin{array}{l}9 \text { bis } 10 ; 7 \text { lahre } \\
\text { (1;7 Jahre) }\end{array}$ & Vollremission & - \\
\hline 2. Episode Anfang 1949 & $\begin{array}{l}\text { 10;7-10;10 Jahre } \\
\text { (3 Monate) }\end{array}$ & $\begin{array}{l}\text { Rezidivierende depressive Störung, } \\
\text { gegenwärtig schwere Episode mit } \\
\text { psychotischen Symptomen } \\
\text { (F33.3/296.34) }\end{array}$ & - \\
\hline Intervall 2. Hälfte 1949 & $\begin{array}{l}\text { 10;10 bis } \\
11 ; 5 \text { lahre } \\
\text { (7 Monate) }\end{array}$ & Vollremission & - \\
\hline 3. Episode Ende 1949 & $\begin{array}{l}\text { ca. } 11 ; 5-11 ; 7 \text { Jahre } \\
\text { (2 Monate) }\end{array}$ & $\begin{array}{l}\text { Rezidivierende depressive Störung, } \\
\text { gegenwärtig mittelgradige Episode mit } \\
\text { somatischen Symptomen } \\
\text { (F33.11/296.32) }\end{array}$ & - \\
\hline Intervall Anfang 1950 & $\begin{array}{l}\text { 11;7-12;5 lahre } \\
\text { (10 Monate) }\end{array}$ & Vollremission & - \\
\hline $\begin{array}{l}\text { 4. Episode Nov. } 1950 \text { bis } \\
\text { April } 1951\end{array}$ & $\begin{array}{l}\text { 12;5-12;10 lahre } \\
\text { (5 Monate) }\end{array}$ & $\begin{array}{l}\text { Rezidivierende depressive Störung, } \\
\text { gegenwärtig schwere Episode mit } \\
\text { psychotischen Symptomen } \\
\text { (F33.3/296.34) }\end{array}$ & - \\
\hline $\begin{array}{l}\text { Intervall April } 1951 \text { bis } \\
\text { Juni } 1962\end{array}$ & $\begin{array}{l}\text { 12;10-24 Jahre } \\
\text { (11;2 Jahre) }\end{array}$ & $\begin{array}{l}\text { Partielle Remission mit dysthymer } \\
\text { Störung (F34.1/300.4) }\end{array}$ & - \\
\hline
\end{tabular}




\begin{tabular}{|c|c|c|c|}
\hline Zeitraum & Alter & Diagnose & Behandlung \\
\hline $\begin{array}{l}\text { 5. Episode Juni } 1962 \text { bis } \\
\text { Sept. } 1962\end{array}$ & $\begin{array}{l}\text { 24-24;3 Jahre } \\
\text { (3 Monate) }\end{array}$ & $\begin{array}{l}\text { Rezidivierende depressive Störung, } \\
\text { gegenwärtig schwere Episode mit } \\
\text { psychotischen Symptomen } \\
\text { (F33.3/296.34) }\end{array}$ & $\begin{array}{l}\text { Neuroleptika, } \\
\text { ES }\end{array}$ \\
\hline $\begin{array}{l}\text { 6. Episode Sept. } 1962 \text { bis } \\
\text { Feb. } 1963\end{array}$ & $\begin{array}{l}24 ; 3-24 ; 8 \text { Jahre } \\
\text { (5 Monate) }\end{array}$ & $\begin{array}{l}\text { Paranoide Episode } \\
\text { (F20.0/295.3) }\end{array}$ & $\begin{array}{c}\text { Antidepressiva, } \\
\text { ES }\end{array}$ \\
\hline $\begin{array}{l}\text { Intervall Feb. } 1963 \text { bis } \\
\text { Juli } 1963\end{array}$ & $\begin{array}{l}24 ; 8-25 ; 1 \text { lahre } \\
\text { (5 Monate) }\end{array}$ & $\begin{array}{l}\text { Schizophrenes Residuum } \\
(20.5 / 295.6)\end{array}$ & Neuroleptika \\
\hline $\begin{array}{l}\text { 7. Episode Juli } 1963 \text { bis } \\
\text { Nov. } 1963\end{array}$ & $\begin{array}{l}25 ; 1-25 ; 5 \text { lahre } \\
\text { (4 Monate) }\end{array}$ & $\begin{array}{l}\text { Schizoaffektive Störung, } \\
\text { gegenwärtig depressiv } \\
\text { (F25.1/295.7) }\end{array}$ & $\begin{array}{l}\text { Neuroleptika, } \\
\text { Antidepressiva }\end{array}$ \\
\hline $\begin{array}{l}\text { Intervall Nov. } 1963 \text { bis } \\
\text { Juni } 1966\end{array}$ & $\begin{array}{l}25 ; 5-28 ; 0 \text { lahre } \\
\text { (2;7 lahre) }\end{array}$ & $\begin{array}{l}\text { Schizophrenes Residuum } \\
\text { (F20.5/295.6) }\end{array}$ & Antidepressiva \\
\hline $\begin{array}{l}\text { 8. Episode Juni } 1966 \text { bis } \\
\text { November } 1966\end{array}$ & $\begin{array}{l}\text { 28;0-28;5 lahre } \\
\text { (5 Monate) }\end{array}$ & $\begin{array}{l}\text { Paranoide Episode } \\
\text { (F20.0/295.3) }\end{array}$ & Neuroleptika \\
\hline $\begin{array}{l}\text { Intervall Nov. } 1966 \text { bis } \\
\text { April } 1967\end{array}$ & $\begin{array}{l}28 ; 5 \text { bis } \\
28 ; 10 \text { lahre } \\
\text { (5 Monate) }\end{array}$ & $\begin{array}{l}\text { Schizophrenes Residuum } \\
\text { (F20.5/295.6) }\end{array}$ & Neuroleptika \\
\hline $\begin{array}{l}\text { 9. Episode April } 1967 \text { bis } \\
\text { Okt. } 1968\end{array}$ & $\begin{array}{l}\text { 28;10-30;4 Jahre } \\
\text { (1;6 Jahre) }\end{array}$ & $\begin{array}{l}\text { Schizoaffektive Störung, } \\
\text { gegenwärtig depressiv } \\
\text { (F25.1/295.7) }\end{array}$ & Neuroleptika \\
\hline $\begin{array}{l}\text { Intervall Okt. } 1968 \text { bis } \\
\text { Juni } 1969\end{array}$ & $\begin{array}{l}\text { 30;4-31;0 Jahre } \\
\text { (8 Monate) }\end{array}$ & $\begin{array}{l}\text { Schizophrenes Residuum } \\
\text { (F20.5/295.6) }\end{array}$ & - \\
\hline $\begin{array}{l}\text { 10. Episode Juni } 1969 \text { bis } \\
\text { Juni } 1972\end{array}$ & $\begin{array}{l}\text { 31;0-34;0 Jahre } \\
\text { (3 Jahre) }\end{array}$ & $\begin{array}{l}\text { Schizoaffektive Störung, } \\
\text { gegenwärtig depressiv } \\
\text { (F25.1/295.7) }\end{array}$ & Neuroleptika \\
\hline $\begin{array}{l}\text { Intervall Juni } 1972 \text { bis } \\
\text { Juli } 1987\end{array}$ & $\begin{array}{l}\text { 34;0-49;1 Jahre } \\
\text { (15;1 Jahre) }\end{array}$ & $\begin{array}{l}\text { Schizophrenes Residuum } \\
\text { (F20.5/295.6) }\end{array}$ & Neuroleptika \\
\hline $\begin{array}{l}\text { 11. Episode Juli } 1987 \text { bis } \\
\text { Mai } 1994\end{array}$ & $\begin{array}{l}\text { 49;1-55;11 Jahre } \\
(6 ; 10 \text { lahre) }\end{array}$ & $\begin{array}{l}\text { Paranoide Schizophrenie (F20.0/295.3), } \\
\text { schizophrenes Residuum (F20.50/295.6), } \\
\text { kontinuierlicher Verlauf }\end{array}$ & Neuroleptika \\
\hline
\end{tabular}

Bei der Patientin ist also ein eindrucksvoller Übergang der Psychopathologie vom Affektiven zum Schizophrenen im Alter von 24 Jahren zu beobachten, wobei die affektive Symptomatik bemerkenswert früh, bereits im Alter von 9 Jahren, begann. Die Abfolge der verschiedenen psychopathologischen Episoden und Zustände ist in Abbildung 7 nochmals graphisch dargestellt.

Auch in der Aszendenz kam beides vor: Die Mutter litt an einer endogenen Depression, die Großmutter mütterlicherseits wurde 11 Jahre lang wegen einer Schizophrenie behandelt und verstarb in einem Psychiatrischen Landeskrankenhaus. Der jüngste von drei Brüdern der Patientin war wiederholt in stationärer psychiatrischer Behandlung wegen einer paranoid-halluzinatorischen Schizophrenie mit agitiert-depressiv-hypo- 
chondrischen Zügen behandelt worden, er wies also eine ähnliche Symptomatik auf wie die Patientin selbst!

Die schizophrene Psychopathologie ab dem Alter von 24 Jahren war sehr vielgestaltig und umfasste wahnhafte Bedeutungs- und Beziehungsideen, Gedankenlautwerden, optische Halluzinationen, Entfremdungserlebnisse, Beeinflussungsideen, die Patientin glaubte u.a., dass sie absichtlich von anderen gequält werde und litt unter heftigen Suizidimpulsen. Die 1. und 2. schizophrene Episode im Alter von 24 und 25 Jahren dauerte jeweils 4 Monaten, die 3. im Alter von 28 Jahren 5 Monate. Im Alter zwischen 28,10 und 30,4 Jahren war die Symptomatik durch das gleichzeitige (konkurrente) Nebeneinander von schizophrenen und affektiven Symptomen gekennzeichnet:

- inhaltliche und formale Denkstörungen,

- Ich-Erlebensstörungen,

- Veränderungserlebnisse,

- Beeinflussungs- und Bedeutungsideen und

- heftige Suizidimpulse.

Daneben ängstlich-depressive Verstimmungszustände, vorwiegend im Frühjahr. Im Alter von 31-34 Jahren 3 Jahre lang anhaltende schizoaffektive Phase wechselnder Akuität. Die Patientin sieht u.a. „überall Augen, die mich ganz böse ansehen“. Im Alter von 39 Jahren schizoaffektive Psychose mit formalen Denkstörungen, Wahnvorstellungen, taktilen und optischen Halluzinationen, subdepressiver Stimmung. Dauer: 6 Monate.

Bei der Nachuntersuchung im Alter von 56 Jahren besteht eine starke postpsychotische Wesensänderung mit Reduzierung von Antrieb und beeinträchtigter emotionaler Modulationsfähigkeit. Nach wie vor bestehen optische und akustische Halluzinationen, Gedankenlautwerden, paranoide Beziehungsideen, Versündigungsideen, Minderwertigkeitsideen und Beeinflussungsideen (Gedanken werden durch das Fernsehen beeinflusst, sie wird vom Fernseher beauftragt, etwas zu singen und Aufträge auszuführen, wobei sie die Botschaften aus dem Fernsehgerät auch hört). Schlechte Sozialremission.

Auch bei dieser Patientin ist die Symptomkonstanz bemerkenswert: Sowohl in den depressiven, als auch in der schizoaffektiven und schizophrenen Phasen bzw. Episoden klagt sie über Erstickungsängste, Vorstellungen, eine Nadel verschluckt zu haben und sieht Gesichter, die sie verfolgen.

Wenn man die bisherigen Verlaufsbeschreibungen synoptisch zusammenfasst und die Heterogenität der beschriebenen Krankheitsbilder zu ordnen versucht, so lassen sich ganz grob drei Patientengruppen herausarbeiten:

1. Eindeutig schizophrene Patienten mit gelegentlichen affektiven (depressiven, manischen, bipolar manisch-depressiven) Symptomen und Phasen

2. Patienten mit eindeutigen affektiven Störungen und gelegentlich auftretenden schizophrenen Symptomen oder Episoden

3. Patienten, bei denen das Verhältnis von schizophrenen und affektiven Symptomen und Episoden im Querschnitt und im Längsschnitt in etwa ausgeglichen ist.

Sowohl unter phänomenologischen (Querschnittsbetrachtung) als auch verlaufstypologischen Aspekten lassen sich also Gemeinsamkeiten bzw. „Überschneidungen“ 


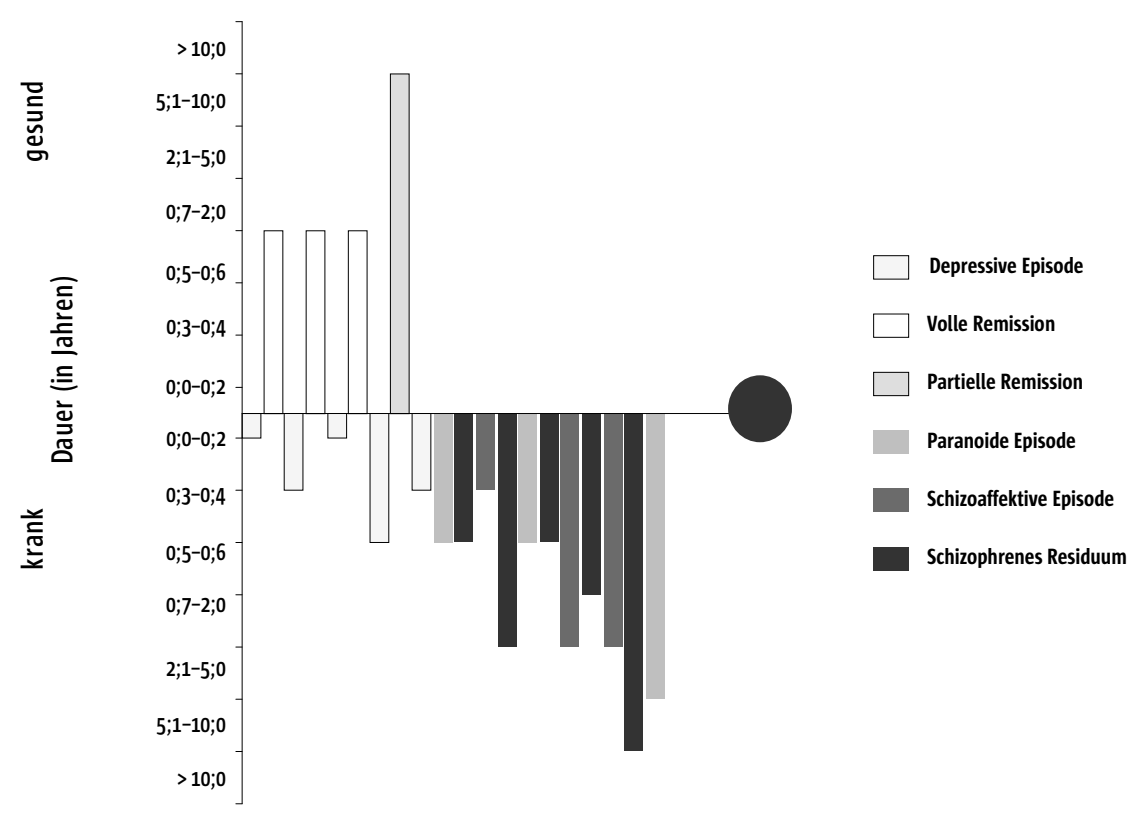

Episoden

Abb. 7 Abfolge der verschiedenen Krankheitsstadien in einem Zeitraum von 47 Jahren

in Bezug auf schizophrene und affektive Syndrome beobachten. Insbesondere sprechen molekulargentische Untersuchungen dafür, dass es Überschneidungen zwischen schizophrenen und affektiven Psychosen gibt. So erhöhen Varianten des Neuregulin 1 (NRC1)-Gens das Manifestationsrisiko sowohl für schizophrene als auch für affektive Psychosen, dies gilt vor allem auch für das Disrupted in Schizophrenia 1 (DISC1)-Gen (Hodgkinson et al. 2004, OWEN et al. 2007) (s. auch Kap. 12.2).

Die 10 schizoaffektiven Patienten der 2. Untersuchungsstichprobe ( $n=44$, durchschnittliche Nachbeobachtungszeit: 42 Jahre) erreichten folgende Remissionsgrade:

- 5 Voll-Remissionen (DAS: $1-2$ )

- 2 Teil-Remissionen (DAS: $3-4)$

- 3 Schizophrenes Residuum (DAS: 5-6)

Dies entspricht einer relativ günstigen Gesamtprognose schizoaffektiver Psychosen des Kindesalters im Langzeitverlauf und steht in Übereinstimmung einer früheren Untersuchung an 16 schizoaffektiven Psychosen des Kindesalters (Eggers 1989) sowie mit Ergebnissen bei erwachsenen Patienten, welche gezeigt haben, dass die Prognose schizoaffektiver Psychosen besser ist als bei schizophrenen, jedoch ungünstiger als bei affektiven Psychosen (Harrow et al. 2000, Marneros 2008, Malhi et al. 2008).

Bei den 3 Patienten, die ein schizophrenes Residuum (F 20.5, 295.6) entwickelt hatten, war die affektive Symptomatik in eine vorherrschende schizophrene Symptomatik übergegangen. In einer vergleichenden Musteranalyse bei 16 schizoaffektiven Psychosen im Vergleich zu 41 rein schizophrenen Psychosen des Kindes- und Jugendalters zeigte sich, dass letztere signifikant längere Krankheitszeiten aufwiesen (Bunk und Eggers 1990). 
Darüber hinaus bestand eine signifikante positive Korrelation zwischen dem Auftreten von Residualzuständen und der Frequenz langdauernder schizophrener Episoden $(\mathrm{r}=0.40 ; \mathrm{p}=0.008)$ bzw. mit einer langen Dauer anhaltender schizophrener Symptomatik $(r=0.57 ; p=0.02)$. Dagegen bestand eine signifikant negative Korrelation zwischen postpsychotischen Defizienzzeichen und Frequenz der Episoden $(\mathrm{r}=-0.61$; $\mathrm{p}=0.01$ ). Das spricht dafür, dass kurzdauernde affektive und schizoaffektive Episoden und die Abwesenheit langdauernder schizophrener Episoden mit einer günstigen Prognose einhergehen.

Einen Überblick über die Phasendauer schizophrener ( $n=41)$ im Vergleich zu schizoaffektiven Psychosen ( $n=16)$ unserer ersten Untersuchungsstichprobe ( $\mathrm{n}=57$, durchschnittliche Nachbeobachtungszeit 15 Jahre) gibt Tabelle 17.

\section{Tab. 17 Dauer der Phasen (in Monaten)}

\begin{tabular}{l|cccccc} 
& $n$ & Streubreite & Median & $\begin{array}{c}\text { Weniger als } \\
6 \text { Monate }\end{array}$ & $\begin{array}{c}\text { Mehr als } \\
6 \text { Monate }\end{array}$ & Summe \\
\hline $\begin{array}{l}\text { Schizoaffektive } \\
\text { Psychosen }\end{array}$ & 16 & $0,5-60$ & 3 & $103(93 \%)$ & $8(7 \%)$ & 111 \\
\hline $\begin{array}{l}\text { Schizophrene } \\
\text { Psychosen }\end{array}$ & 41 & $0,5-204$ & 4,28 & $101(67 \%)$ & $50(33 \%)$ & 151 \\
\hline
\end{tabular}

Auch aus Tabelle 17 ist ersichtlich, dass über 90\% der Phasen schizoaffektiver Psychosen nur maximal 6 Monate andauerten. Demgegenüber hielten zwei Drittel der schizophrenen Episoden bis zu 6 Monate und ein Drittel mehr als 6 Monate an.

Ein weiterer Unterschied zwischen stilrein schizophrenen und schizoaffektiven Psychosen ist die höhere Phasen- bzw. Episodenfrequenz im Verlauf schizoaffektiver gegenüber schizophrenen Psychosen (s. Tab. 18)

Tab. 18 Anzahl der Phasen

\begin{tabular}{|c|c|c|c|c|c|}
\hline & $\mathrm{n}$ & Streubreite & Median & Mittelwert (X, S) & Summe \\
\hline $\begin{array}{l}\text { Schizoaffektive } \\
\text { Psychosen }\end{array}$ & 16 & $1-15$ & 7 & $6,9 \pm 3,3$ & 111 \\
\hline $\begin{array}{l}\text { Schizophrene } \\
\text { Psychosen }\end{array}$ & 41 & $1-15$ & 4 & $3,7-3,2$ & 151 \\
\hline
\end{tabular}

Bei den meisten Patienten kamen im Verlauf schizophrene, schizoaffektive und affektive Phasen gemeinsam vor (8 Patienten). 5 Patienten wiesen nur schizoaffektive, manisch-depressive oder rein depressive Phasen auf. Bei 3 Patienten kamen im Verlauf ihrer Psychose abwechselnd rein schizophrene und bipolare manisch-depressive affektive Phasen mit und ohne psychotische Symptome, jedoch keine schizoaffektiven Phasen mit konkurrenten (gleichzeitigen) schizophrenen und affektiven Symptomen vor (s. Tab. 19). 
Tab. 19 Kombination von schizophrenen, schizoaffektiven und manisch-depressiven Phasen bei 16 Patienten

\begin{tabular}{ll}
\hline Schizophrene und schizoaffektive Episoden & 8 Patienten \\
\hline Schizoaffektive und manisch-depressive und/oder depressive Phasen & 5 Patienten \\
\hline Schizophrene und bipolar manisch-depressive Phasen & 3 Patienten \\
\hline
\end{tabular}

Zyklothyme Symptome können bei Kindern und Jugendlichen als Prodromalerscheinungen vor dem Einsetzen schizophrener Psychosen vorkommen, in Form von kurzdauernden depressiven, manisch-depressiven und manischen Verstimmungen, die der Psychose in der Regel einige Tage bis Wochen vorauslaufen und dann kontinuierlich in die schizophrene Erkrankung übergehen. Die kurzfristigen prodromalen Stimmungsschwankungen erreichen nicht den Schweregrad von bipolar-affektiven Störungen (F 31) oder rezidivierenden depressiven Störungen ( $\mathrm{F} 33$ ).

Solche zyklothymen Prodrome sind jedoch nicht so selten und kamen bei 13 Kindern der ersten Untersuchungsstichprobe $(n=57)$ vor. Bei ihnen dominierte der schizophrene Charakter der Erkrankung ganz eindeutig, sodass diese Verläufe nicht als schizoaffektiv bezeichnet werden können. Die manische Symptomatik war jeweils durch drangvolle Getriebenheit, Überaktivität mit Arbeitswut, Logorrhoe, Inkohärenz des Gedankenganges und Lockerung der assoziativen Bezüge, durch euphorisch gehobene Stimmungslage, übertriebene Lustigkeit und Schlaflosigkeit, teilweise in Kombination mit Sendungs- und Größenideen gekennzeichnet. So kamen bei einem 13-jährigen Mädchen manische Prodrome 3mal in 28tägigen Abständen vor, bevor die paranoid-halluzinatorische Psychose mit Symptomen ersten und zweiten Ranges nach K. Schneider ausbrach. Die manisch-depressiven Prodrome waren durch gleichzeitiges Vorkommen von Traurigkeit, Verzweiflung, Suizidabsichten, Todes- und Krankheitsfurcht, starke Selbstvorwürfe, Selbstbeschuldigungs- und Versündigungsideen, extreme Stimmungsschwankungen, Appetit- und Schlafstörung, Apathie, Rückzug auf der einen Seite und maniforme Symptome (Logorrhoe, gehobene Stimmung, exaltiertes Gebaren, dranghafte Unruhe, Widersetzlichkeit, Größenideen) auf der anderen Seite gekennzeichnet.

Hinsichtlich prämorbider Wesensauffälligkeiten zeigte sich ein deutlicher Unterschied zwischen den schizophrenen und den schizoaffektiven Patienten. Letztere wiesen nur in knapp einem Drittel prämorbide Auffälligkeiten auf (Introversion, Scheu, Gehemmtheit, Furchtsamkeit, Unsicherheit, Kontaktarmut), während knapp 6o\% der schizophrenen Kinder als auffällig einzustufen waren. Dies entspricht auch Befunden bei schizophrenen Erwachsenen (Saracco-Alvarez et al. 2009).

Zwischen schizophrenen und schizoaffektiven Psychosen gibt es auch Unterschiede auf neuropsychologisch- neurophysiologischer Ebene, z.B. im Bereich ereigniskorrelierter Potentiale. Die P3oo ist eine späte Komponente ereigniskorrelierter akustisch evozierter Potentiale, welche dann auftritt, wenn im Rahmen gleichförmiger Standardtöne neue, abweichende Stimuli dargeboten werden, z.B. infrequente eingestreute Töne, die beachtet werden sollen. Die P3oo tritt etwa $300 \mathrm{~ms}$ nach dem abweichenden Stimulus auf. Die P3oo- Komponente stellt ein elektrophysiologisches Korrelat der gezielten Aufmerksamkeit dar. Eine Reduktion der Pzoo Ampiltude ist ein typischer neurophysiologischer Befund, der bei schizophrenen Patienten immer wie- 
der beschrieben wurde und auf gestörte Aufmerksamkeitsprozesse hinweist. Die Latenz bis zum Auftreten der $\mathrm{P}_{3}$ oo ist ein Maß für die Verarbeitungsgeschwindigkeit und -effizienz bei der Reizwahrnehmung und -einordnung. Während schizophrene Patienten sowohl Amplitudenminderungen als auch Latenzverzögerungen aufweisen, sind bei Patienten mit schizoaffektiven Störungen nur Latenzverzögerungen, nicht aber Reduktionen der P300-Amplitude zu beobachten, was dafür spricht, dass die Ressourcenkapazität für die Beachtung neuer, ungewöhnlicher Stimuli bei schizoaffektiven Psychosen nicht beeinträchtigt ist (Mathalon et al. 2010). 